\title{
EMES AND COVID-19: \\ SHUTTING DOWN IN A WORLD OF INFORMAL AND TINY FIRMS
}

\author{
Laura Alfaro \\ Oscar Becerra \\ Marcela Eslava \\ Working Paper 27360 \\ http://www.nber.org/papers/w27360
NATIONAL BUREAU OF ECONOMIC RESEARCH
1050 Massachusetts Avenue
Cambridge, MA 02138
June 2020

The views expressed herein are those of the authors and do not necessarily reflect the views of the National Bureau of Economic Research.

NBER working papers are circulated for discussion and comment purposes. They have not been peer-reviewed or been subject to the review by the NBER Board of Directors that accompanies official NBER publications.

(C) 2020 by Laura Alfaro, Oscar Becerra, and Marcela Eslava. All rights reserved. Short sections of text, not to exceed two paragraphs, may be quoted without explicit permission provided that full credit, including $\left({ }^{\circ}\right.$ notice, is given to the source. 
EMEs and COVID-19: Shutting Down in a World of Informal and Tiny Firms

Laura Alfaro, Oscar Becerra, and Marcela Eslava

NBER Working Paper No. 27360

June 2020

JEL No. F0,O17,O20,O47

\begin{abstract}
Emerging economies are characterized by an extremely high prevalence of informality, smallfirm employment and jobs not fit for working from home. These features factor into how the COVID-19 crisis has affected the economy. We develop a framework that, based on accounting identities and actual data, quantifies potential job and income losses during the crisis and recovery for economies with different economic organization structures. Our analysis incorporates differential exposure of jobs across categories of firm-size and formality status, as well as sectors and occupations. We account for the direct supply shock caused by lockdowns, the idiosyncratic demand shock suffered by sectors that rely on high contact with their costumers, the transmission of both shocks through IO linkages, and the overall aggregate demand effect derived from these shocks. Applying our framework to data for Colombia, which exhibits an employment distribution similar to that of other emerging market countries, in particular Latin America, we find that well over 50\% of jobs are at risk in the initial stages of the crisis. Because informal jobs and those not fit for telework are at higher risk, this number goes down to $33 \%$ if the US employment distribution is imposed on the Colombian data. As the crisis deepens, the risk of unemployment grows. However, informality rebounds quickly in the recovery, an employment at risk is quickly reduced to $20 \%$ of the baseline, all concentrated in formal jobs. Our findings point to the importance of action to maintain formal matches from dissolving, given their scarcity and rebuilding difficulty, while protecting the poor and the informal via income transfers.
\end{abstract}

Laura Alfaro

Harvard Business School

Morgan Hall 263

Soldiers Field

Boston, MA 02163

and NBER

lalfaro@hbs.edu

Oscar Becerra

Universidad de los Andes

Calle 19A No 1-37 Este. Office W-824

Bogota

Colombia

obecerra@uniandes.edu.co
Marcela Eslava

Universidad de los Andes

Calle 19A \# 1-37 Este. Bloque W of. 810

Bogotá, Colombia

meslava@uniandes.edu.co 


\section{Introduction}

Informality and employment in microenterprises are prevalent in emerging and developing countries, accounting for over $50 \%$ of the labor force in many of them. Informal workers lack employment protection. Those in very small firms, not all of which are also informal, are more exposed to job losses than those in larger firms, as the former are less able to continue paying workers in the absence of income. Moreover, workers in poorer countries locate in occupations less fit for telework, given low education levels, greater concentration of workers in the production of low-sophistication goods and services, and low connectivity.

Given these differential features, workers in emerging economies, are exposed to immediate labor income losses in the face of physical-distancing policies to limit the effects of the pandemic, and less able to self-isolate in the absence of mandatory lockdowns. The overall impact on livelihoods is starker in these countries because automatic stabilizers via the social security system are weak, frequently even nonexistent. On the other hand, informal jobs come back to life in a recovery phase more easily than do jobs in formal firms, which, unlike them, depend on high organizational and physical capital, and are subject to entry, exit and hiring costs of regulation.

In this paper, we assess the vulnerability of employment and income to the COVID-19 crisis in emerging and poorer markets relative to the developed world. Our comparison accounts for the distribution of workers across sectors, firm size categories, and occupations. In our framework, the risk of losing one's income increases as the duration of the crisis progresses. This is because employers, who act as insurers by continuing to pay payroll expenses in markets with firing and layoff restrictions, erode their cash reserves as time passes. Larger companies tend to have more cash reserves and better access to credit than smaller firms and are thus better able to continue paying employees. ${ }^{1}$

We consider exposure to the economic effects of the crisis that depends on the following mechanisms. First, a direct supply shock emerging from lockdowns will affect primarily sectors producing non essentials (e.g. apparel). ${ }^{2}$ In any sector affected by closures, however, a worker is less exposed to income/job losses if she usually works from home or her occupation is such that she can telecommute. Second, an idiosyncratic (domestic) demand shock can result from a reduction of demand for specific goods and services as a result of the health emergency. This affects primarily sectors dependent on face-to-face interactions with customers, such as hotels or theaters and, to a lesser extent, restaurants and non-essential retail. Third, the previous effects can be amplified by input-output (IO) linkages. Finally, we consider overall income reductions caused by the above channels affecting all sectors, creating a Keynesian aggregate demand multiplier effect. ${ }^{3}$

\footnotetext{
${ }^{1} \mathrm{~A}$ recent survey by Bartik et al. (2020) documents the small cash reserves for small businesses in the U.S., in emerging markets, it is often less than three weeks. See Section 3.1 for a description of the Colombian context.

${ }^{2}$ Besides lockdown, supply shocks include other policy regulations (like work protocols for functioning businesses), and also voluntary closures in the absence of lockdown measures.

${ }^{3}$ In this sense, our approach relates to that of Farhi and Baqaee $(2019,2020)$ who also incorporate these different
} 
In our environment, informal and self-employed workers are most exposed, to the point that they can lose their income sources as soon as the crisis hits and/or confinement/quarantine is in place. This is because they are not protected by links to an employer bound by firing restrictions or other employment protection regulations. The next most-affected are formal workers in smaller firms, and finally those in larger firms. The high prevalence of informality and employment in small firms in EMEs thus implies higher vulnerability to the economic effects of the crisis, in particularly the risk of immediate income and job losses.

Paradoxically, informal jobs and informal businesses are relatively easily recoverable because they face minimal organization capital and entry, hiring and firing costs. In many EMEs, these costs are substantial, implying labor market rigidities that increase the duration of unemployment spells. Though formal firms, particularly the large ones, are more resistant to initial shocks, they suffer disadvantages during protracted downturns. Recovering the lost value from destroyed formal jobs and formal firms, for which organizational capital is highly valuable and hard to rebuild and labor and corporate regulations are binding, is much more difficult than recovering informal jobs.

We quantify and analyze the effects of the aforementioned four different channels for the case of Colombia, which is representative of Latin America and other EMEs in terms of having a labor market with extremely high informality and a high concentration of workers in self-employment and very small firms. We then run a counterfactual analysis by assuming that workers are relocated across occupations, sectors and firm size categories to mimic the distributions of a developed economy, with minimal informality and a lesser prevalence of employment in microenterprises and in occupations unfit for telework. In terms of policies, we focus on lockdowns, which have been the prevalent approach to deal with the pandemia in most EMEs. ${ }^{4}$

We find that, compared to baseline data for 2019, as many as $56 \%$ of jobs and $43 \%$ of aggregate value added are at risk in the initial stages of the crisis. Because the informal sector is at higher risk, these numbers go down to $33 \%$ and $30 \%$, respectively, if the distribution of employment in the U.S. is imposed on the Colombian data. As the crisis deepens, employment at risk grows to $67 \%$, (60\% under the U.S. distribution). Informality rebounds quickly during recovery, however, and employment at risk is quickly reduced to $20 \%$ of the baseline, while under the U.S. distribution (but maintaining labor market rigidities such as in Colombia) risk would remain at $40 \%$ in the initial recovery phase.

Our work relates to a broader literature aiming to understand the difference in firm heterogeneity across nations and its role for aggregate activity. Researchers have documented that, in dimensions of the economic shock.

${ }^{4}$ TTI expansion is clearly on the agenda, and probably should be prioritized, but it has faced de facto constraints in light of limited capabilities of the governments in EMEs to access testing kits. Age policies, in turn, are subject to questions. First, most elderly live with their families, especially in EMEs and developing economies, so that they are exposed to contagion when any member of the family is exposed. In Colombia, close of $70 \%$ of those over 65 live in households with members under that age. Second, age policies may not be constitutional, as they limit liberties in light of criteria that are discriminatory. 
manufacturing, average firm size is smaller, and the firm size distribution is much more concentrated in the far lower tail in less developed economies in comparison to the developed world (Tybout, 2000; Hiseh and Klenow, 2009; Poshke, 2018). That fact has been recently traced back to a lower average life cycle growth of manufacturing establishments in developing countries, driven especially by poorer dynamics in super star plants (Hsieh and Klenow, 2014; Eslava, Haltiwanger and Pinzon, 2019). More recently, the prevalence of small firm employment in developing economies has been shown to hold for sectors other than manufacturing, and be particularly acute in certain services sectors (e.g. Alfaro and Eslava, 2020; Alfaro, Charlton and Kanczuk, 2009). ${ }^{5}$ A large literature links the prevalence of small firms and small firm employment to the existence of distortions to the optimal allocation of resources. Much of this literature aims at quantifying the magnitude and distribution of the distortions implicit in the firm size distribution in developing vs. developed economies (e.g. Hsieh and Klenow, 2009; Bento and Restuccia, 2020). In this paper we show that the fact that the size and growth distribution are shifted to the left has important economic and policy implications for the management of crises in emerging markets.

As such, our paper relates to a rapidly emerging literature studying the aggregate economic consequences of COVID-19. The theoretical literature on the economics of pandemics is already vast. ${ }^{6}$ Here, we focus on the vulnerability of individuals based on data on the full distribution of occupations and type of employment, using accounting identities. In that sense, our work is closer to recent papers studying the evolution of the labor market and employment trends during the COVID19 pandemic (Cajner et al. 2020 and Coibion et al. 2020)), and those focusing on small businesses (Humphries et al. 2020 and Bartik et al. 2020). Several researchers have provided estimates of the supply shock from labor supply (Dingel and Neiman, 2020; Koren and Petot, 2020; Leibovi et al. 2020). Compared to these works, our methodological innovation is the joint consideration of demand, supply shocks and multiplier effects in an empirical framework that highlights the role of informality and small firms.

Indirect amplification have been also analyzed by Barrot et al. (2020) who focus on the distancing effects in a model of production networks, and analyze the sectoral effects of the shock for France. Baqaee and Fahri (2020 a, b) among others, advance the theoretical implications of network models in the COVID context and analyze quantitative counterfactuals. In contrast to these theoretical approaches, ours builds on accounting identities and observed characteristics of labor markets, entry and exit and firm-organization modes, and policy responses to the epidemics,

\footnotetext{
${ }^{5}$ Consistent with this, Bento and Restuccia (2020) show that average firm size is smaller in services than manufacturing. Alfaro and Eslava (2020) also find that, although the distribution of firm sizes is shifted to the left relative to developed economies in all sectors, and shifted to the left in services relative to manufacturing in all countries, the developing-developed gap is smaller in services than in manufacturing.

${ }^{6}$ See Acemoglu et al. (2020), Alvarez et al. (2020), Atkenson (2020), among others. Alfaro, Faia, Lamersdorf, and Saidi (2020) modify the SIR model to include agents' optimizing decisions on social interactions. Susceptible individuals internalize infection risk based on their patience, infected ones do so based on their fear and altruism, and reciprocity matters for internalizing risk.
} 
focusing on emerging markets.

Alon et al (2020) also incorporate differences betwen more and less developed economies. They offer a contrast between countries with different demographics and prevalence of informality, in terms of the evolution of contagion and economic outcomes in the crisis. Our focus, meanwhile, is on job and labor income losses, under exposure differentials associated with the structure of the economy across sectors, occupations, and business organization modes. We also have a different take on informality. While in Alon et al.'s environment informal sector workers are individual units which can operate even under lockdown policies, we model an informal sector that, as has been the case in the predominant urban areas of Latin America, is affected by lockdowns. ${ }^{7}$ Rather than segmented, informal and formal activities in many EMEs form an integrated market in which firms and workers interact based on their comparative advantage and regulation barriers (Meghir, Narita, Robin, 2015). Informal workers have in fact been a major concern, and the focus of mitigation efforts during the crisis in EMEs. While lockdown measures have indeed been ineffective in many rural and isolated areas across the world, and in some urban areas in the poorest countries, we see this more as an expression of lack of state presence than a consequence of informality per se.

Our work also relates to Barrero et al. (2020) who focus on the reallocation effects of the COVID19 shock. Alfaro, Chari, Greenland and Schott (2020) link the seemingly conflicting narratives from the stock and labor markets based on the disease progression, showing that day-to-day changes in the predictions of standard models of infectious disease forecast changes in aggregate stock returns in pandemics and investors views regarding firms capacities to adjust and cut costs.

Different economic structures between wealthy and poorer countries factor into how the crisis affects the economy and optimal policy options. Informality, prevalent in emerging markets, and firm size distribution tilted towards micro-enterprises, should be considered when designing the response to the pandemic. The urgency of protecting livelihoods of the poor and informal suggests that income transfers for this population should be immediately considered, as has in fact been done in many Latin American countries. Meanwhile, measures aimed at alleviating income losses for formal workers may be insufficient. Avoiding the loss of formality, especially in environments where formal jobs and firms are scarce, is of the foremost importance. Moreover, given the limits to the fiscal capabilities of states, this will only be possible if health strategies such as testing and tracing are expanding at a sufficiently rapid pace to reduce the need for extended lockdowns.

Section 2 presents our conceptual and empirical frameworks. The context in Colombia, data and the measurement strategy builds on the first sections and are discussed in detail in Section 3. We present our results in sections 4 and 5, first describing the Colombian labor market in light of our measures of exposure, and then quantifying potential job and value added losses. We close with a discussion of implications in the last section.

\footnotetext{
${ }^{7}$ Urbanization rates are not too different in Latin America nowadays compared to the developed world. For 2018, for instance, close to $82.3 \%$ of population in the United States lived in urban areas, not far from the $80.5 \%$ on average in Latin America, and $80.7 \%$ in Colombia.
} 


\section{Framework}

\subsection{Conceptual Framework}

We develop an accounting framework to assess the vulnerability of employment and income to the COVID-19 crisis. Our framework is based on data at the level of individual workers who had a job at the beginning of the crisis, including information on the industry and occupation for each employee, as well as the size of the firm for which they worked (including the possibility of a one-person firm for, e.g., the self-employed).

We assume that the economic risk for different workers and incomes depends on a variety of attributes of the jobs, the sectors and the firms to which they were attached before the crisis. In particular, we evaluate the role of four attributes: formality/informality, firm size, economic sector, and occupation.

Labor informality is a lack of compliance with labor regulations. Informal jobs are much more flexible than formal ones, both in terms of separations and hirings. They are not covered by employment protection mechanisms, including firing restrictions and severance payments. This means they will be harder hit at the beginning of the crisis, potentially from its very onset. They also open up easily, because they rely on low organizational and physical capital, which means that in a recovery phase they are likely to come to life before other jobs do. Formal jobs in formal firms, meanwhile, take time to recover, and may even never do so.

Firm-size is a determinant of the likelihood that the worker loses their job. For a job to survive in a period where income is not generated, the employer has to either use its cash reserves or access credit. Medium and large firms typically have both larger cash reserves and more access to credit, which implies that they can keep employment for longer periods. Meanwhile smaller firms have much more limited reserves and frequently no access to credit, so they are affected more rapidly. Once the shocks that gave birth to the crisis are gone, it is more likely that larger formal firms survived, so jobs attached to them may recover faster than those in smaller formal firms. Both, however, are more difficult to recover than informal jobs.

Some economic sectors are more vulnerable than others in the presence of lockdowns, due to the nature of the lockdown policies applied to mitigate the health crisis. In the case of Colombia, sectors producing and distributing essential goods and services, such as food or internet services, are less vulnerable, and so are the jobs in those sectors, because they are typically allowed to continue operating. This was also the case for sectors that are most easily transferred to the virtual world, such as education and professional services. ${ }^{8}$ In the absence of lockdowns, sectors where buyers are exposed to high contact with other people, such as hotels, restaurants and retail stores, are at risk of facing demand reductions. The next section explains in detail the policies adopted.

\footnotetext{
${ }^{8}$ Arguably, preschool and primary education are less conducive for virtual education. It also affects the ability of caregivers to go to back to contact jobs and limits online work.
} 
The occupations that require high physical contact and that are not fit for telework are at higher economic risk, regardless of the firm-size and the economic sector. The inability to operate virtually makes them more susceptible to lockdowns and demand contractions.

For each worker, we consider exposure to the following shocks and mechanisms of transmission of the effects of the crisis:

First, a direct supply shock that occurs when the sector in which the worker is in cannot operate due to lockdowns (primarily sectors producing non-essentials) and the worker is not in an occupation that is fit for telework. While there may be additional supply shocks due to voluntary closures of businesses, we currently do not evaluate them due to a lack of relevant data. Worker illness related to the pandemic from another potential supply-side shock. Up to mid-May, however, the spread of the virus has been modest in Colombia ( $15 \mathrm{~K}$ identified cases and less than 600 deaths, for a population of 50 million), so that this shock has not been sizeable.

Second, a direct idiosyncratic demand shock that occurs when demand falls specifically for the sector that depend on face-to-face interactions with customers (e.g. hotels or theaters and, to a lesser extent, restaurants and non-essential retail).

Along with the direct shocks, we also consider indirect supply and demand shocks that refer to the indirect effect of lockdown shocks because either downstream or upstream sectors (or both) are affected directly by lockdowns, and the indirect effect of direct demand shocks because upstream sectors are affected by the direct demand shock (i.e. the food chain affected by lower demand at restaurants and hotels).

Finally, all of the previous shocks are amplified by an aggregate demand multiplier due to income reductions implied by the above channels, which affect demand in all sectors.

\subsection{Accounting Framework}

\subsubsection{Aggregation}

We use three different metrics for welfare-related outcomes that we calculate at the two-digit level of aggregation: employment, labor income, and value added. For each individual $i$ who had a job at the baseline, employment $\left(L_{i}=1\right)$ and labor income $W_{i}$ are directly reported in the data for the baseline case (actual 2019 data). Defining $F_{i}=\{0,1\}$ as an indicator that individual $i$ was in a formal job at baseline, we generate the at-risk number of formal, informal, and total workers in sector $s$, under different scenarios, as: 


$$
\begin{aligned}
\text { Lrisk }_{\text {st }}^{\text {formal }} & =\sum_{i \in s} \pi_{i t} \times F_{i} \times L_{i} \\
\text { Lrisk }_{s t}^{\text {Informal }} & =\sum_{i \in s} \pi_{i t} \times\left(1-F_{i}\right) \times L_{i} \\
\text { Lrisk }_{s t} & =\text { Lrisk }_{\text {st }}^{\text {formal }}+\text { Lrisk }_{\text {st }}^{\text {Informal }} .
\end{aligned}
$$

$\pi_{i t} \in[0,1]$ measures the probability that worker $i$ loses her job or income due to the crisis in period $t$, taking into account the four dimensions of shocks previously discussed. $t$ is a stage in the advance of the crisis.

We similarly generate at risk aggregate labor income (formal, informal, and total) and value added in sector $s$ as

$$
\begin{aligned}
& W r i s k_{s t}^{\text {formal }}=\sum_{i \in s} \pi_{i t} \times F_{i} \times W_{i} \\
& W r i s k_{s t}^{\text {Informal }}=\sum_{i \in s} \pi_{i t} \times\left(1-F_{i}\right) \times W_{i} \\
& W r i s k_{s t}=W_{s t}^{\text {formal }}+W_{s t}^{\text {Informal }} \\
& V \text { Arisk }_{s t}=W_{s t} \times\left(\frac{V A^{I O}}{W^{I O}}\right)_{s} \text {, }
\end{aligned}
$$

where $\left(\frac{V A^{I O}}{W^{I O}}\right)_{s}$ is the ratio of value added to labor income in $s$, obtained from the IO matrix. We finally aggregate across sectors to obtain aggregate measures of employment and value added: $V A=\sum_{s} V A_{s}=\sum_{s} \sum_{i \in s}\left[W_{i} \times\left(\frac{V A^{I O}}{W^{I O}}\right)_{s}\right]$.

\subsubsection{Economic Exposure}

For any individual $i$ who worked in sector $s$ at baseline, her own exposure to potential income losses from alternative crisis scenarios depends on an array of characteristics of her occupation and the sector. We define the probability that $i$ losses her job and income, $\pi_{i t} \in[0,1]$, as:

$$
\pi_{i t}=\min \left\{1,\left(S_{-} \operatorname{shock}_{i t}+D_{-} \operatorname{shock}_{s}\right) \times A D\right\}
$$

where $S_{-}$shock $_{i t}$ is a supply shock affecting $i$ 's job, $D_{-}$shock $k_{s}$ is a demand shock affecting her sector, and $A D$ is an aggregate demand shock. $S_{-}$shock $_{i}$ depends on whether person $i$ 's sector is in, or its customer or supplier sectors, is forced to shut down on-site activities; whether her occupation is not fit for telework or requires high contact; and whether she is an employee at a 
large or small firm. In particular

$$
S \_s h o c k_{i t}=S_{i t} \times \min \left\{1,\left(1-T_{i}\right)+H i g h \_ \text {contact }_{i}\right\} \times \min \left\{1, \text { Lock }_{s}+L \_u p_{s}+L \_ \text {down }\right\}
$$

$T_{i}$ is the probability that $i$ can telework, while High_contact $t_{i}$ is the probability that her job requires high physical contact with others, both calculated based on $i$ 's occupation. $S_{i t}=0$ if $i$ works for a firm large enough that it does not need to fire its workers in period $t$ even if it is not generating income (because, for instance, it can rely on cash reserves to continue paying workers). Lock $_{s}=0$ if sector $s$ is among those allowed to continue operating under the lockdown, for different lockdown scenarios. If the sector is not allowed to operate, $L o c k_{s}=1 . L \_u p_{s}$ captures the indirect effect of a lockdown through reduced or closed operations at customer sectors ( $s$ is up from $j$ ), and $L \_d o w n_{s}$ captures the indirect effect through providers ( $s$ is down from $j$ ). More explicitly:

$$
\begin{aligned}
L_{-} u p_{s} & =\sum_{j \neq s} \text { Lock }_{j} \times \frac{\text { purchases }_{j: \text { from }_{\text {s }}}}{\text { grossout }_{s}} \\
L_{-} \text {down }_{s} & =\sum_{j \neq s} \text { Lock }_{j} \times \frac{\text { purchases }_{s: \text { from }: j}}{\text { grossout }_{s}}
\end{aligned}
$$

Notice that a sector that is allowed to continue on-site operations during lockdowns $\left(\operatorname{Lock}_{s}=0\right)$ will still be exposed to the lockdown shock of downstream and upstream sectors. And workers in sectors affected by the lockdown are not subject to the supply shock if they can telework and their occupations do not require high physical contact with probability one. However, if lockdowns do not affect the sector either directly or through IO linkages, i.e. $\min \left\{1, \operatorname{Lock}_{s}+L \_u p_{s}+L \_d o w n_{s}\right\}=$ 0 , workers in that sector are not affected by lockdowns, independent of their ability to telework. That is, in this case $S \_s h o c k_{i t}=0$.

As discussed above, we assume that jobs in larger firms take longer to be affected by the crisis, because those firms have both cash reserves and access to credit on which they can rely to continue payments to workers. In particular, denoting the number of workers at the firm where $i$ works as $S_{i}^{f i r m}$, and adopting the convention that $S_{i}^{f i r m}=1$ for self employed and informal workers, we assume the following sequencing for the crisis period, where $t$ is an indicator for stages of process:

$$
\begin{aligned}
& S_{i t}=1 \text { if } S_{i}^{\text {firm }} \leq 10 \text { and } 1 \leq t \\
& S_{i t}=1 \text { if } 10<S_{i}^{\text {firm }} \leq 50 \text { and } t \geq 2 \\
& S_{i t}=1 \text { for all } i \text { if } t \geq 3
\end{aligned}
$$

and $S_{i t}=0$ otherwise. The 10 and 50 employees thresholds are somewhat arbitrary, but aim at defining micro, small, and medium-large firm size categories. They follow the cutoffs with which size categories used to be defined by law in Colombia for the targeting of policies aimed at firms. ${ }^{9}$

\footnotetext{
${ }^{9}$ Size categories are currently defined in terms of assets rather than employees in the country.
} 
We also incorporate "recovery" phases in the analysis. These are characterized by the lifting of all lockdown measures and the end of idiosyncratic demand shocks, but may still exhibit employment losses relative to baseline because of search frictions and firm entry costs due to which creating formal jobs and opening new firms takes time. Informal firms and the self-employed recover more easily, as they depend on themselves for going back to work. But recovering formal jobs takes longer, especially for small (but formal) firms. We thus incorporate two recovery phases, "initial" and "advanced", where, starting from $S_{i t}=1$ for all workers, we set

$$
\begin{aligned}
& S_{i t}=0 \text { if } i \text { informal or self-employed for both phases } \\
& S_{i t}=0 \text { if } 50<S_{i}^{f i r m} \text { and } t=\text { advanced recovery }
\end{aligned}
$$

D_shock $k_{s}$ is an indicator of the fraction of demand lost for sector $s$ as a result of its customers' choice to self isolate, considering both final and intermediate customers. It is computed as:

$$
D_{-} \text {shock }_{s}=\text { Dloss }_{s} \times \frac{\text { finalsales }_{s}}{\text { grossout }_{s}}+\sum_{j} \text { Dloss }_{j} \times \frac{\text { purchases }_{j: \text { from:s }}}{\text { grossout }_{s}},
$$

where $D_{l o s} s_{s}$ is the fraction of final demand lost in sector $s$. We compute Dloss based on sales contractions of consumer goods and services observed in countries where lockdowns were not implemented. Dloss $_{s}=0$ for all intermediates, but notice that even for these sectors $D \_s h o c k_{s}>0$ if the final goods sectors to which they sell experience demand contractions. For instance, textile producers are hit by the contraction of sales in apparel and accessories.

The aggregate demand shock, meanwhile is modeled through a standard Keynesian multiplier, which takes into account heterogeneity in the population and higher marginal propensity to consume among poorer households:

$$
A D=\sum_{\text {income }} \rho_{\text {income }} \times \frac{1}{1-M P C_{\text {income }}} .
$$

We simulate different lockdown scenarios. For each of these, we initially compute our welfare metrics using the actual distribution of workers across sectors, firm sizes $S_{i}$, and occupations $\left(T_{i}\right.$ and High_contact $\left.{ }_{i}\right)$. We then relocate workers across these dimensions based on counterfactual distributions that simulate a developed economy. 


\section{Context, Data and Measurement}

\subsection{Context: Colombia}

Similar to other EMEs, especially in Latin America, Colombia has high informality rates. Depending on the measure of informality used, between $47 \%$ and $61 \%$ of jobs in the country are informal, over $95 \%$ of them either consist of self-employment or firms of less than 10 workers. Over $45 \%$ of workers are self-employed, many of them also informally. More than $80 \%$ of the population live in urban centers (WDI, 2019), which is close to the average of Latin American countries.

Informal jobs do not comply with labor market regulations, like mandatory social security contributions and other non-salary labor costs, and are not covered by employment protection mechanisms, like firing restrictions. Non-salary costs imposed by the regulations represent increases in labor costs of over $40 \%$ for employers, while the minimum wage to which all formal jobs are subject is high enough to approach the median income of workers. Firing restrictions include limits to the fraction of workers that can be fired without permission by the Ministry of Labor and mandatory compensation to fired workers. Unemployment insurance in Colombia is extremely weak, granting one minimum monthly wage once in a lifetime, and up to six months of continued public health and pension coverage. Workers in the formal sector who become unemployed are entitled to severance payments. All of these sources of rigidities in the labor market imply that the loss of formal jobs is likely to be persistent.

The pandemic hit Colombia in the second half of March, with the first case reported on March 6th, 2020. The lockdown in Colombia has been strict. Starting on March 21st, other than the production and distribution of essentials, and their inputs, all sectors were ordered to stop in-situ operations. Schools and universities closed. People were not allowed to exercise or be outdoors except to buy essentials. Many cities imposed restrictions based on gender or national ID numbers, so that a person could buy groceries, for instance, only once every four or five days. On May 1st, some of the measures were partially eased. In particular, a few manufacturing and construction firms were allowed to go back to work, and previous approval of on-the-job safety and social distancing plans varied by firm. In several cities, these approvals took up to two weeks to be obtained, so that openings did not become realistic until mid-May. At that point, other manufacturing sectors were also allowed to request approval of their social distancing protocols. Openings have been uneven across regions, with some cities being more willing and effective in allowing and regulating the reopening of authorized activities than others. This lighter lockdown has been extended to the beginning of June. It has been announced that schools will not return to classes before August, and international travel will be banned at least until September.

Colombians initially closely complied with the lockdown. As time has passed, observance of the measures has deteriorated, especially with the informal sectors going back to work. With streets semi-empty, street vendors and beggars go door-to-door. 
The economy has already been hit hard. By April 30th, 5.3 million jobs, equivalent to $25 \%$ of pre-crisis employment, had been lost. Growth in the first quarter was $1.1 \%$, despite an estimated $4.6 \%$ growth in January and February. Expectations for April, with full lockdowns in place for the entire month were extremely low. The economic mitigation package has included transfers to informal workers and poor families, building on the pre-existing social transfers system; public credit guarantees of $90 \%$ for payroll payments by businesses; and more recently grants to support payroll payments for firms hit hard by the crisis. The overall size of the package, which remains timid by international standards, is currently valued at $3 \%$ of GDP in spending with an additional line of up to $5 \%$ in guarantees.

One dimension of contrast with other Latin American economies is that the pandemic hit Colombia at a time when economic prospects were relatively bright. The country's GDP per capita ( $\$ 15,000$ in PPP terms) is similar to that of Brazil, and slightly below that of Chile and Mexico (\$20,000 PPP). Since 2010, Colombia has been growing close to 1.5 percentage points above the average of Latin America and the Caribbean annually, despite the country being hard hit by the decline in oil prices around 2015 (oil represents close to 50\% of income from exports and over 10\% of government revenue). In January, 2020, the IMF projected that Colombia would grow $3.5 \%$ in 2020. Capital flight and impossibility for EMEs' governments to issue new debt have been pointed at as a potential consequence of the crisis. However, this concern has become effective mainly for countries whose fiscal situation was already under stress. Colombia was relatively well placed to start with, and has in fact successfully issued debt in international markets well into the crisis. ${ }^{10}$

\subsection{Employment Characteristics}

Our main source of data is the Colombian household survey GEIH ("Gran Encuesta Integrada de Hogares") for 2019. The GEIH, collected by the Colombian Bureau of Statistics, DANE, is the basis for official statistics on the labor market, including the measurement of unemployment.

We obtain employment, labor income, individual characteristics and employment characteristics, from the GEIH. This survey records whether the person has a job, and in which sector (at a four-digit level of disaggregation of the ISIC revision 4 classification); whether they are salaried or self-employed; the size of the firm in which the individual works; and her occupation among 83 minor occupational categories (following the ISCO-68 classification). Information about formality/informality status, such as whether the worker and her employer comply with mandatory social security contributions, is recorded. The data also allow us to identify whether the person works from home, at a fixed location out of home (an office, production plant, construction site, etc), or on the streets (driving or as a street vendor); and the transportation mode the individual most frequently uses to go to work. The survey is representative at a national level, and for each of 23

\footnotetext{
${ }^{10}$ On June 1st, 2020, for instance, the government announced it successfully placed long run bonds for $\$ 2,500$ at rates below $4.2 \%$.
} 
metropolitan areas in the country. It is not designed to be representative of the labor force at the sector level, yet it is the official source used to report employment statistics by economic sector and its results square with sector statistics from administrative records.

From a conceptual standpoint, labor informality is the lack of compliance with labor regulations. Given the variety of labor regulations with which workers and employers must comply, there is no single operative definition of labor informality. We settle here for a definition based on compliance with pensions contributions, which in Colombia are mandatory for any worker. Paying the contribution is the shared responsibility of the worker and her employer, each of whom must pay a fraction of the mandatory contribution. In particular, we label a worker as informal when she is not contributing to the pension system, except when she is retired, in which case she is not mandated to contribute. This is a strict definition of informality because, when a worker and her employer comply with the worker's pension contribution, they generally also comply with the other relevant regulations (Bernal, 2009). Informality is prevalent in the country: in 2019, close to $60 \%$ of workers were informal according to this definition. Although there are less strict operational definitions of informality, all point to extremely high levels, in general above $50 \%{ }^{11}$

\subsection{Occupations: Fit for Telework vs. High Physical Contact}

For equation (3), our measures of the probability that the worker can work from home and the probability that she is exposed to high physical contact are based on reports of her occupation and her journey to work in GEIH. Our measure of the probability of telework, $T_{i}$, is based in Dingel and Neiman (2020). Dingel and Neiman classify 478 occupational categories in the American Community Survey, which follows the Standard Occupational Classification (SOC), as either fit for telework or not. Given that the classification of occupations in the Colombian GEIH is much less granular, we aggregate SOC classes to the level of GEIH occupational categories. We then obtain for each of those categories the fraction of US workers in the American Community Survey whose SOC occupational class is classified as fit for telework. $T_{i}$ is computed as equal to the fraction for the GEIH occupational category that $i$ is in.

We follow a similar procedure to compute the probability that $i$ works in a high contact occupation (denoted $\mathrm{HCjob}_{i}$ ). As proxy for high contract, we use the share of US workers in GEIH occupations that are classified as medium and high contact by Leibovici, Santacreu and Famigleti (2020). Combining $\mathrm{HCjob}_{i}$ with the indicator of whether in $2019 i$ regularly used public trans-

\footnotetext{
${ }^{11}$ Following International Labor Organization's statistical standards, the official measure of informality produced by DANE is based on the number of workers employed at firms of 5 workers or less and independent non-professional workers. This is a proxy for informality, as not all informal employees are in firms of these characteristics, and not all micro firms fail to comply with labor regulations. This official measure generates a lower, but still very high figure for informality: close to $50 \%$ over 2019 .
} 
portation to get to work in the GEIH, we obtain our measure of High_contact ${ }_{i}$ for equation (3)

$$
H i g h \_ \text {contact }_{i}=H_{C j o b_{i}}+U s e s \_P u b \_ \text {Transport }_{i}-H C j o b_{i} \times U s e s \_P u b \_ \text {Transport }_{i} .
$$

\subsection{IO linkages}

To compute the indirect supply and demand shocks in equations (5) and (8), we complement the data from GEIH with the Colombian 2015 IO matrix. The IO matrix follows the National Accounts sector classification, which has a slightly higher level of aggregation than ISIC two-digit. We use the IO matrix not only to incorporate IO linkages into our analysis, but also to obtain sector level labor/capital income ratios that we use to approach sector value added from the reports of labor income in the GEIH.

\subsection{Measurement of Demand Shocks}

To measure idiosyncratic demand shocks we rely on data on the behavior of the demand of different consumer goods and services in Sweden. We take advantage of the fact that Sweden did not impose lockdowns to deal with the COVID-19 crisis to isolate effects related to the change of consumer behavior. The data come from McKinsey (2020) consumer survey, where consumers are asked to report whether in April 2020 they increased or decreased spending relative to normal times, for a series of categories of goods and services. We equate Dloss s to the fraction of consumers who report a decrease net of the fraction of consumers that reported an increase. Since the data refer only to consumer goods and services, we impose $\operatorname{Dloss}_{s}=0$ for all sectors producing only intermediates. Notice from equation (8) that even for these sectors $D_{-}$shock $k_{s}>0$, the final goods sectors to which they sell experience demand contractions. For instance, leather producers are hit by the contraction of sales in apparel and accessories. Appendix Table A1 shows net changes in spending by product category in Sweden according to McKinsey (2020), which we match to the ISIC sectors in GEIH.

As for the aggregate demand multiplier (9), in the absence of reliable estimates of the $M P C$ for Colombia and other EMEs, we rely on $M P C_{\text {income }}$ estimates by quintile of income in the US by Carrol et al. (2017). Wide income differences between Colombia and the US are recognized by setting $\rho_{\text {income }}$ to the fraction of workers that in Colombia fall within each of U.S. income bracket. In fact, over $90 \%$ of workers in the Colombian household survey exhibit income levels that fall in the lowest quintile of the U.S. distribution. Table 1 documents our $M P C$ levels and the fractions of workers in each bracket. The resulting AD multiplier is 1.692 . 
Table 1: Monthly labor income and Marginal Propensity to Consume

\begin{tabular}{|c|c|c|c|c|c|c|}
\hline \multirow{3}{*}{$\begin{array}{c}\text { Labor } \\
\text { Income } \\
\text { Quintiles }\end{array}$} & Ave. Income & Min. Income & Ave. Income & Min. Income & \multirow{2}{*}{$\begin{array}{l}\text { Workers in } \\
\text { Category }\end{array}$} & \multirow{3}{*}{$\mathrm{MPC}$} \\
\hline & \multicolumn{4}{|c|}{ From US Income Distribution } & & \\
\hline & \multicolumn{2}{|c|}{$\mathrm{US} \$(2016)$} & \multicolumn{2}{|c|}{ COP (thous.) } & $\%$ & \\
\hline $0-20$ & 15,657 & 13 & 4,122 & 3.4 & 99.4 & 0.41 \\
\hline $20-40$ & 41,491 & 30,041 & 10,923 & 7,908 & 0.43 & 0.21 \\
\hline $40-60$ & 71,712 & 54,858 & 18,879 & 14,442 & 0.11 & 0.23 \\
\hline $60-80$ & 129,544 & 94,042 & 34,104 & 24,758 & 0.03 & 0.21 \\
\hline $80-100$ & $1,127,782$ & 186,778 & 296,901 & 49,172 & 0.01 & 0.18 \\
\hline
\end{tabular}

Notes: The resulting AD multiplier is 1.692. MPC taken from Carroll et al. (2017). Source for

Colombia income distribution and employment, Colombia Statistical Office (GEIH data).

\section{The Labor Market}

Table 2 presents basic statistics of our data, and reflects basic characteristics of the Colombian labor market in 2019. Column 1 shows statistics pooling sectors, while columns 2 and 3 divide the sample between sectors least and most vulnerable to lockdown. The least vulnerable sectors are those producing essentials, plus education and professional services, a good part of which have continued operating remotely. ${ }^{12}$ The detailed classification of the sectors least and most vulnerable to lockdowns is presented in Appendix Table A2, together with a characterization of each.

Table 2: Employment, labor income and value added by vulnerability to lockdown

\begin{tabular}{lrrr}
\hline & Total & $\begin{array}{c}\text { Sectors Least } \\
\text { Vulnerable to } \\
\text { Lockdown }\end{array}$ & $\begin{array}{c}\text { Sectors Most } \\
\text { Vulnerable to } \\
\text { Lockdown }\end{array}$ \\
\hline Employment (mill.) & 22.3 & 12.8 & 9.5 \\
Monthly total labor income (trill. of COP) & 22.0 & 13.8 & 8.2 \\
Monthly average labor income (thous. COP) & 989 & 1,079 & 869 \\
Monthly value added (trill. of COP) & 77.4 & 49.3 & 28.1 \\
Monthly value added per worker (thous. COP) & 3,474 & 3,857 & 2,957 \\
Informal (mill.) & 13.6 & 7.2 & 6.5 \\
Self-employed (mill.) & 10.1 & 5.4 & 4.7 \\
At firm <10 employees (mill.) & 15.6 & 8.3 & 7.2 \\
At firm 11-50 employees (mill.) & 1.8 & 0.9 & 0.8 \\
Average IO linkages index & 1.66 & 1.67 & 1.63 \\
Average \% Decline Sales of G\&S, Sweden ${ }^{1}$ & 0.10 & 0.05 & 0.16 \\
Average idiosyncratic demand shock & 0.15 & 0.10 & 0.20 \\
Average supply shock & 0.50 & 0.18 & 0.92 \\
\hline April 2020 against previous year (normal). Source: for Colombia income and employ- \\
ment, Colombia Statistical Office (GEIH data). & & &
\end{tabular}

The total number of workers in Colombia in 2019 reached 22.3 million. The average worker earned slightly less than one million Colombian Pesos a month (close to \$300). A key characteristic

\footnotetext{
${ }^{12} \mathrm{~A}$ detailed classification of the sectors least and most vulnerable to lockdowns and their general characteristics are presented in Appendix Tables A2 to A4.
} 
of the Colombian labor market is that, similar to other emerging economies, most of the employment concentrates in informal activities and small firm production. Out of the 22.3 million workers, 61\% (13 million) have informal jobs as identified by failure to comply with mandatory pension contributions, while $70 \%$ (15.5 million) work in a firm with at most 10 employees. This includes a self-employed workers, who represent $45 \%$ of all. By contrast, self-employment in the US accounts for just around $10 \%$ of workers.

As in other developing economies, especially in Latin America, informality in Colombia cannot be fully explained as the byproduct of poverty. It is rather a state to which many workers and firms reallocate given their comparative advantage and regulation barriers (Magnac, 1991; Maloney, 1999)). Table 3 presents characteristics of employment in Colombia for the formal and informal sector. Being informal and working in tiny production units are highly correlated phenomena. $64 \%$ of informal workers are self-employed, while an additional $31 \%$ are employees in small firms, so that only $5 \%$ work at firms with more than 10 employees. Meanwhile, among formal workers only $16 \%$ are self-employed and an additional $14 \%$ are employees in firms with at most 10 workers, so that $70 \%$ work in firms of larger size.

Table 3: Attributes of jobs for formal and informal workers (Shares,\%)

\begin{tabular}{lrr}
\hline & Formal & Informal $^{1}$ \\
\hline Self-Employed & 15.8 & 64.2 \\
At firms $\leq$ 10 employees & 30.3 & 95.1 \\
At firms 11-50 employees & 15.2 & 3.2 \\
Bottom labor income quartile & 6.1 & 41.3 \\
Second labor income quartile & 5.7 & 35.0 \\
Third labor income quartile & 39.8 & 13.9 \\
Top labor income quartile & 48.4 & 9.9 \\
Affiliated to contributory health care system & 95.9 & 7.1 \\
Has occupational safety and health & 91.5 & 3.2 \\
Has a contract & 89.6 & 33.5 \\
Has a verbal contract (if has contract) & 5.9 & 90.8 \\
High contact job & 84.6 & 86.7 \\
Can telework & 21.4 & 10.5 \\
With labor income under minimum wage & 10.0 & 68.0 \\
\hline I A worker is labeled as informal if their mandatory pension contri- \\
butions are not paid. Source: Colombia Statistical Office (GEIH \\
data).
\end{tabular}

Most informal workers are in the bottom part of the earnings distribution, with $35 \%$ of them in the bottom quartile. Meanwhile, almost half of formal workers are in the top earnings quintile. However, there is a significant overlap between the earnings distributions for formal and informal workers up to the third quartile of labor earnings. As we pointed out in the definition of our measure of formality, non-compliance with mandatory contributions to the pension system is often related to non-compliance with other mandated contributions, such as a contributory health care 
system, occupational health and safety, compliance with minimum wage laws, and even having a written contract. Less than $10 \%$ of workers we classify as informal pay health contributions, only $3 \%$ have access to occupational safety and health, $68 \%$ report monthly earnings below the statutory minimum wage, and a third of them have any contract, over $90 \%$ of which are verbal. Among formal workers, meanwhile, almost all have written contracts, pay health contributions, report earnings above the statutory minimum wage, and report access to occupational safety and health. Colombia, thus, replicates the prevalence and features of informality that also hold for other Latin American and developing economies (Perry et al., 2007; La Porta and Shleifer, 2014; Meghir et al., 2015). In that sense, it is a good laboratory in which to analyze the differential impact that the crisis may cause in countries with labor market characteristics typical of EMEs.

The different underlying characteristics of sectors and occupations determine economic vulnerability. Figure 1 summarizes dimensions of economic vulnerability to complement Table 2, splitting sectors into those we deem most and least vulnerable to lockdowns. These detailed dimensions by sector are shown in Appendix Tables A2 to A4.

Comparing sectors least and most vulnerable to lockdowns in Table 2 and Figure 1, we find high correlation between vulnerability to lockdowns and other aspects of economic vulnerability. Workers in more vulnerable sectors account for $43 \%$ of total employment (9.5 million). Sectors more vulnerable to the lockdown are less productive, as measured by both average earnings and value added per worker. Employment in those sectors is also more concentrated on small, informal firms and self-employed workers (mostly informal). $68 \%$ of those workers are informally employed (versus $56 \%$ in less vulnerable sectors), $50 \%$ are self-employed (versus $42 \%$ ), and $76 \%$ work in firms with ten workers or fewer (versus $65 \%$ ). The ability to telework is also less prevalent precisely in sectors most vulnerable to lockdowns ( $8 \%$ versus $20 \%$ in less vulnerable sectors). More and less vulnerable sectors have similar levels of exposure to contact ( 87 versus $85 \%$ ) and similar incidence of workers who regularly work from home (12 versus $10 \%$ ). The combination of these different factors implies that the supply shock (equation 4) is much larger in sectors most vulnerable to lockdowns, affecting $92 \%$ of employment, in contrast to $18 \%$ in less vulnerable sectors. Notice that even the latter are affected by lockdowns via input-output linkages.

Figure 2 summarizes the implications of these characteristics in terms of economic exposure to the crisis (equation 3 ) by sector. The figure depicts average exposure across workers in the sector. Though by construction sectors that we classify as more vulnerable to lockdowns have essentially $100 \%$ exposure, even those that are less vulnerable may face very high exposure levels through demand shocks and IO linkages. The economy's vulnerability is made obvious also by the fact that the sectors that absorb the most employment are among those with high exposure. 
Figure 1: Employment characteristics by sector vulnerability to lockdown

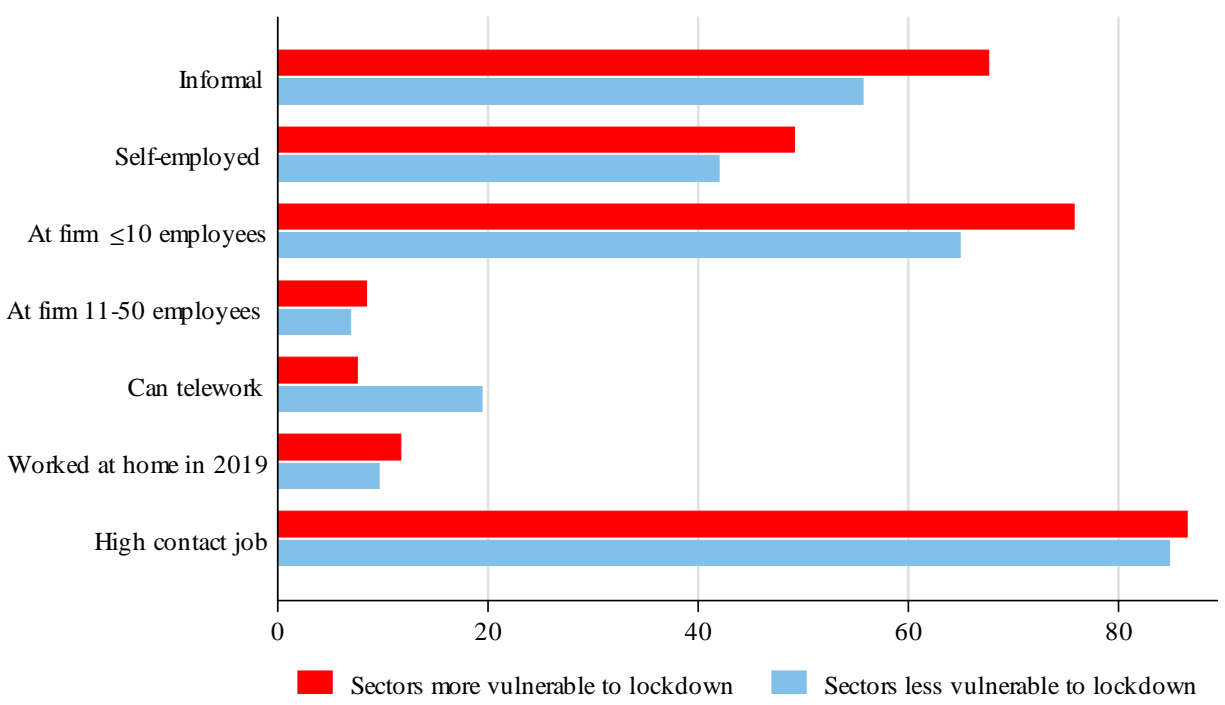

Figure 2: Economic exposure by sector

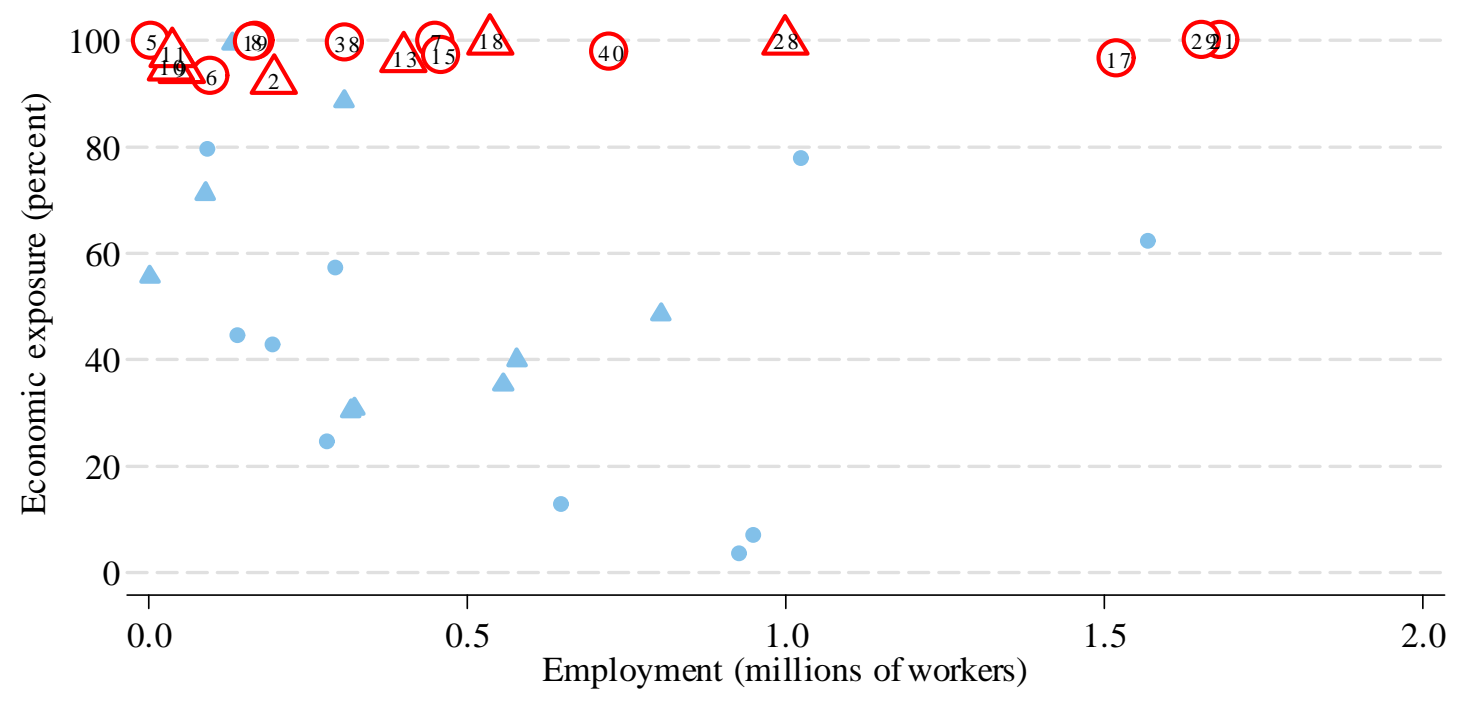

Sectors more vulnerable to lockdown

- Sectors less vulnerable to lockdown

Note: Sectors marked with a triangle are those with the highest linkages (top quartile)

Sectors: 2 Mining and quarrying; 5 Tobacco; 6 Textiles; 7 Wearing apparel; 8 Leather; 9 Wood; 11 Printing and

reproduction of recorded media; 13 Rubber, plastics and metal products; 10 Paper; 15 Machinery and equipment;

17 Construction; 18 Wholesale and Retail of motor vehicles; 19 Wholesale non-basic goods; 21 Retail of non-basic;

goods 28 Transport; 29 Accommodation and food service activities; 38 Arts, entertainment; 40 Activities of households.

The graph does not include sector of agriculture and forestry (less vulnerable) 


\section{Employment in the COVID-19 World}

We now quantify the effect of the crisis, using the accounting framework in section, under two different economic lockdown scenarios: strict lockdown and opening manufacturing and construction.

Under the Strict Lockdown scenario all of the sectors that we labeled as most vulnerable to lockdowns (see Appendix tables for the full list) come to a complete stop, so that Lock $_{s}=1$ for those sectors. This essentially replicates the lockdown in place in Colombia from the end of March to the beginning of May.

Under the Opening Manufacturing and Construction scenario, we ease lockdown allowing manufacturing and construction to open, replicating the easing of the lockdown that Colombia adopted in May (gradually over the course of the month). This reduces the lockdown to non-essential services, including retail and wholesale of non-essentials, and restaurants and hotels. These tend to be the sectors with highest probability of involving high physical contact (see Appendix Table A2). While construction and wood products display as high contact for some of the sectors that remain closed, they were allowed to reopen.

\subsection{Employment at Risk}

Table 4 and Figure 4 present results for the labor market. Table 4 reports jobs at risk. The top panel shows the combined effects of the supply and demand shocks (that is, full exposure as defined in equation 3). To provide a sense of the differential effects of lockdowns over the different phases of the crisis and the subsequent recovery period, rows in the Table cover the different phases described in equations 6 and 7. Both the demand and lockdown shocks remain in place during the crisis periods $(t=1$ to $t=3)$ and vanish in the recovery phases. In the latter, however, jobs recover only progressively given matching frictions and costs for firms to enter.

The sheer magnitude of informality and small firm employment in sectors directly hit and in their customer and provider sectors, implies that an astonishing $56 \%$ of Colombian workers $(12.5$ million) face a potential job and income loss from the very onset of the crisis in the strict lockdown world, given the lack of employment protection for most of these workers and the scarcity of savings and credit for employees and their employers.

As the crisis advances, supply shocks extend to larger firms (see equation 6), so that the number of workers at risk by an extended lockdown eventually reaches 14.9 million (67 percent of total). Even though large firms hold cash and have access to credit, and employment protection regulations supposedly ban them from firing workers without permission, liquidity is limited and the plausibility of relying on credit (both in terms of being granted credit and wanting to demand it) erodes as time under confinement elapses. Larger firms are also more likely to comply with lockdown orders, which in a sense implies that they eventually become potentially more vulnerable than smaller firms and self-employed workers .who more likely bypass such measures. 
Table 4: Jobs at risk under different lockdown measures, compared to baseline 2019 employment

\begin{tabular}{|c|c|c|c|c|}
\hline \multirow{6}{*}{ Phase } & \multicolumn{2}{|c|}{ Total } & \multicolumn{2}{|c|}{ Of which formal } \\
\hline & Strict & Opening & Strict & Opening \\
\hline & Lock- & Manuf. \& & Lock- & Manuf. \& \\
\hline & down & Constr. & down & Constr. \\
\hline & \multicolumn{2}{|c|}{ Millions } & \multicolumn{2}{|c|}{ Share $(\%)$} \\
\hline & \multicolumn{4}{|c|}{ Idiosyncratic Demand \& Lockdown } \\
\hline Early crisis. Informal \& firms $\leq 10$ workers at risk & 12.6 & 10.5 & 23 & 22 \\
\hline Intermediate crisis. Firms $\leq 50$ workers at risk & 13.2 & 10.9 & 25 & 26 \\
\hline Advanced crisis. Firms of all sizes at risk & 14.9 & 11.9 & 32 & 33 \\
\hline Initial recovery. Informal \& self-employed re-enter & 3.8 & 2.5 & 100 & 100 \\
\hline \multirow[t]{2}{*}{ Advanced recovery. Large firms re-enter } & 1.6 & 1.1 & 100 & 100 \\
\hline & \multicolumn{4}{|c|}{ Only Lockdown } \\
\hline Early crisis. Informal \& firms $\leq 10$ workers at risk & 8.5 & 6.3 & 15 & 15 \\
\hline Intermediate crisis. Firms $\leq 50$ workers at risk & 9.2 & 6.7 & 21 & 21 \\
\hline Advanced crisis. Firms of all sizes at risk & 11.0 & 7.8 & 32 & 34 \\
\hline Initial recovery. Informal \& self-employed re-enter & 3.2 & 2.0 & 100 & 100 \\
\hline \multirow[t]{2}{*}{ Advanced recovery. Large firms re-enter } & 1.4 & 0.9 & 100 & 100 \\
\hline & \multicolumn{4}{|c|}{ Only Idiosyncratic Demand Shock } \\
\hline Crisis. Decline in final sales for all sectors & \multicolumn{2}{|c|}{3.2} & \multicolumn{2}{|c|}{28.7} \\
\hline Recovery. Final sales recover & \multicolumn{2}{|c|}{0} & \multicolumn{2}{|c|}{0} \\
\hline
\end{tabular}

Our calculations using official balance sheet data from medium and large firms indicate that in normal times they hold cash and liquid financial assets worth about three months of the combined value of their payroll and rent. ${ }^{13}$

Of course, these are counterfactual calculations that do not take into account possible failures to comply with lockdowns, or government actions to mitigate losses. Thus, they only capture the magnitude of jobs at risk, rather than actual losses. But the finding that for 12.5 million workers their employers (sometimes themselves) were left without income with which to pay their salaries is likely to be close to the reality the Colombian labor market experienced during April 2020, when lockdown measures were most effectively enforced and the government had not yet implemented programs to support firms.

The medium and bottom panels of Table 4 separate the two sources of exposure into the supply shock caused by lockdowns (equation 4) and the demand shock (8). Separating the effect of demand

\footnotetext{
${ }^{13}$ We use Balance Sheet information for all medium and large firms from Supersociedades (the government body in charge of the financial supervision of firms, except those under special regulation), we calculate the median ratio of liquidity to operational income in the sector, where liquidity is the sum of cash and financial current assets. We then multiply this median ration by the median ratio of operational income to find the sum of payroll and rent costs,.This is obtained from DANE's survey of the respective industry (manufacturing, wholesale and retail, or services), which we restrict to only medium and large firms as well, for consistency. The product of these two ratios is our measure of the fraction of a year's worth of payroll and rent that the firm can pay for without generating income.
} 
shocks from that attributed to lockdown-related supply shocks (adjusted for mitigating factors, such as the possibility of working from home), we find that the effects of lockdowns are about three times as large as those related to idiosyncratic demand contractions. The direct effect of shutting down firms and its indirect effects due to input-output linkages represent 8.5 million jobs at risk from the onset of the crisis, even accounting for the potential of telework, that eventually reach 11 million. In contrast, demand shocks (including input-output linkages) have a more modest yet still sizable effect on employment. For the strict lockdown scenario, the reduction in final sales of goods and services associated with social distancing generates an economic exposure of 3.2 million jobs $(14.5 \%$ of total). ${ }^{14}$

In the recovery phase, the high prevalence of informality and self-employment, subject to minimal hiring and setup costs, should allow for a relatively fast recovery of the bulk of employment. In the initial recovery period, where we assume that informal and self-employed workers go back to work, at risk jobs are reduced to nearly 3.8 million. As the recovery stage advances, formal employment in large firms recovers and the jobs at risk are those associated with small formal firms and jobs at risk reduce to about 1.6 million jobs.

Though the extent and design of the lockdown can have significant effects on the magnitude of jobs and income at-risk, the importance of high contact services in the economic structure implies that easing those measures only for the relatively low contact sectors has a quite limited ability to mitigate employment effects. If manufacturing and construction are allowed to reopen, the jobs at risk at the height of the crisis are reduced from 14.9 to 11.9 million.

\subsection{Effects on Value-Added}

We now use the estimated effects on employment summarized in Table to predict effects on value added, and therefore aggregate output, based on the equation system (2), in which we use a proportionality assumption between value added and wages. Under this assumption, we compute the potential of value-added losses based on the labor income of jobs at risk, as displayed in Table 4.

Table 5 presents the results of the monthly value added at risk obtained by using equation (2) and the lockdown scenarios presented in Table 4. As reported in Table 1, the aggregate baseline monthly value added is close to 77 trillion of Colombian Pesos. As much as $43 \%$ of value added (33 trillion COP) per month maybe lost under full compliance with lockdowns, unless, of course, affected firms find ways to continue operating under distancing (i.e. e-commerce for retail sectors). The effects of an extended lockdown could put at risk as much as $60 \%$ of total monthly value added ( 47 trillion) for each additional month that they are in place. Even in the less strict scenario where construction and manufacturing are operating, the value added at risk in the advanced crisis

\footnotetext{
${ }^{14}$ The two separate sources do not add up to the total both because of the aggregate demand effect that transmits through both sources and because of the nonlinearity in the effect implied by the fact that a worker cannot be more than $100 \%$ exposed (equation 3 ).
} 
scenario eventually reaches $45 \%$ of the pre-crisis level (34.5 trillion). Most of the value added at risk is explained by supply shocks (20.8 of the total 33 trillion in the early crisis under strict lockdown), while demand shocks have a relatively small impact on value added ( 8.5 trillion COP in the same case).

Table 5: Total monthly value added at risk under different lockdown measures (assuming full compliance)

\begin{tabular}{|c|c|c|c|c|}
\hline \multirow{6}{*}{ Phase } & \multicolumn{2}{|c|}{ Total } & \multicolumn{2}{|c|}{ Of which formal } \\
\hline & Strict & Opening & Strict & Opening \\
\hline & Lock- & Manuf. \& & Lock- & Manuf. \& \\
\hline & down & Constr. & down & Constr. \\
\hline & \multicolumn{2}{|c|}{ Trillions of COP } & \multicolumn{2}{|c|}{ Share $(\%)$} \\
\hline & \multicolumn{4}{|c|}{ Idiosyncratic Demand \& Lockdown } \\
\hline Early crisis. Informal \& firms $\leq 10$ workers at risk & 33.2 & 26.0 & 42.4 & 38.7 \\
\hline Intermediate crisis. Firms $\leq 50$ workers at risk & 36.5 & 27.8 & 46.1 & 43.5 \\
\hline Advanced crisis. Firms of all sizes at risk & 47.0 & 34.6 & 56.6 & 54.5 \\
\hline $\begin{array}{l}\text { Initial recovery. Informal \& self- } \\
\text { employed re-enter }\end{array}$ & 20.8 & 13.5 & 100 & 100 \\
\hline \multirow[t]{2}{*}{ Advanced recovery. Large firms re-enter } & 8.1 & 5.1 & 100 & 100 \\
\hline & \multicolumn{4}{|c|}{ Only Lockdown } \\
\hline Early crisis. Informal \& firms $\leq 10$ workers at risk & 20.8 & 13.7 & 27.7 & 24.6 \\
\hline Intermediate crisis. Firms $\leq 50$ workers at risk & 24.2 & 15.6 & 36.4 & 35.0 \\
\hline Advanced crisis. Firms of all sizes at risk & 34.3 & 22.1 & 55.3 & 54.1 \\
\hline Initial recovery. Informal \& self-employed re-enter & 16.5 & 10.5 & 100 & 100 \\
\hline \multirow[t]{2}{*}{ Advanced recovery. Large firms re-enter } & 6.4 & 3.9 & 100 & 100 \\
\hline & \multicolumn{4}{|c|}{ Only Idiosyncratic Demand Shock } \\
\hline Crisis. Decline in final sales for all sectors & \multicolumn{2}{|c|}{8.6} & \multicolumn{2}{|c|}{50.6} \\
\hline Recovery. Final sales recover & \multicolumn{2}{|c|}{0} & \multicolumn{2}{|c|}{0} \\
\hline
\end{tabular}

Potential output losses are smaller than employment losses, given the characteristics of sectors and occupations hardest hit by the crisis. As documented in Table 2, jobs in sectors that are most vulnerable to the lockdown have lower average earnings and have a higher probability of being informal than those in less vulnerable sectors. ${ }^{15}$ Since formal-sector jobs tend to be more productive than informal-sector jobs, formal jobs at risks have a disproportionally higher effect on value added.

As a result of these factors, value added at risk accounts for a smaller share of total value added than the share of jobs at risk on total employment. For the same reasons, the rebound in the recovery phases is slower in output than employment. The recovery starts with informal sector employment and self-employment, which implies that it is the less productive workers that come

\footnotetext{
${ }^{15}$ Both groups exhibit a similar value added to wage ratio. Using the figures from Table 2, this ratio is 3.4 in sectors most vulnerable to lockdowns, while it is about 3.6 in the least vulnerable sectors.
} 
Figure 3: Employment characteristics Colombia vs. USA

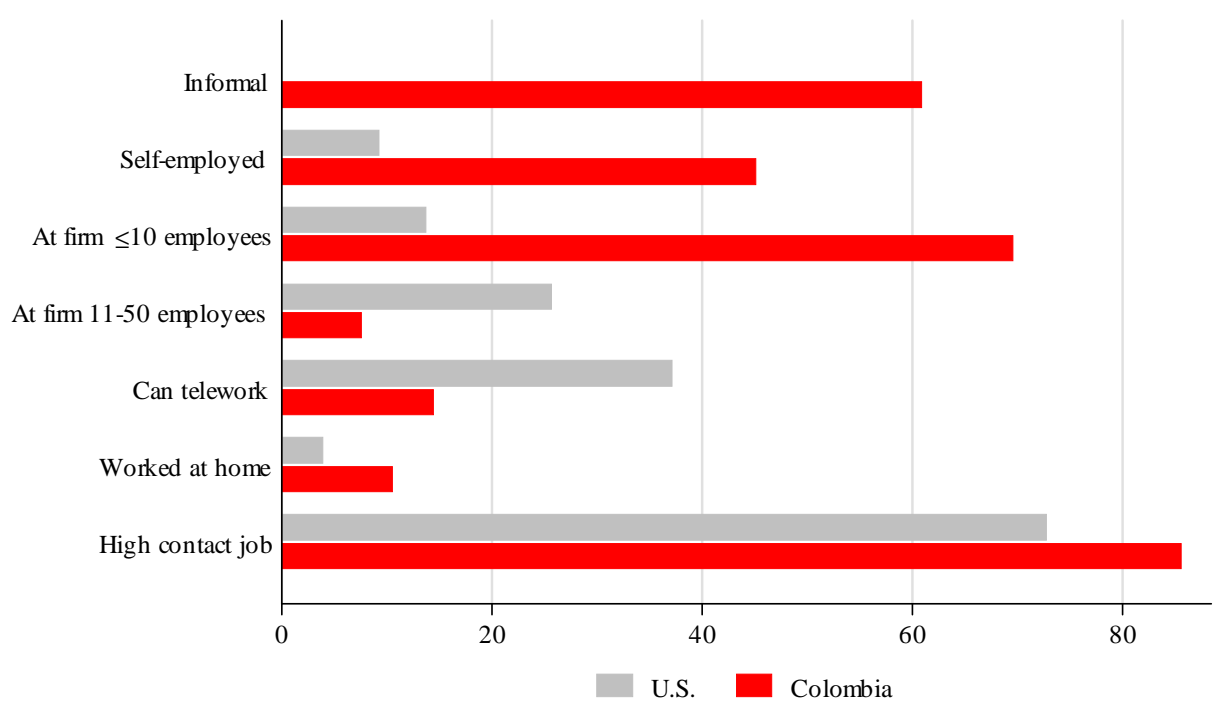

back at this stage. Thus, the share of value added at risk in the initial recovery scenario ( $27 \%$ of the baseline value added) is larger than the share of jobs at risk (17\% of employment in the baseline). These differences vanish as the economy enters to the advanced recovery phase.

\subsection{The Role of the Economic Structure}

The prevalence of informality and the fraction of workers in small firms and occupations not fit for telework is crucial for the magnitude of the effect of the crisis. Developing economies display high informality and high prevalence of employment at small firms, as well as a high concentration of workers in occupations that require them to be in direct contact with customers and co-workers. In high development economies, meanwhile, informality is so irrelevant that, frequently, it is not even measured, large firms absorb the bulk of employment, and many workers are able to work from home, both because of the types of occupations they are in and the much more extensive connectivity to internet.

Figure 3 shows that this is the case for the US, based on data from the American Community Survey. Less than $15 \%$ of U.S. workers are either self-employed or at firms with at most ten employees, by contrast to $70 \%$ in Colombia. While self-employment represents about $10 \%$ of total employment in the US, it represents near $50 \%$ of employment in Colombia. The fraction of those in occupations fit for telework in the U.S. is double that of Colombia, even without factoring in the much greater access to internet in the U.S. 
Figure 4: Jobs at Risk Under Strict Lockdown Measure: All Shocks

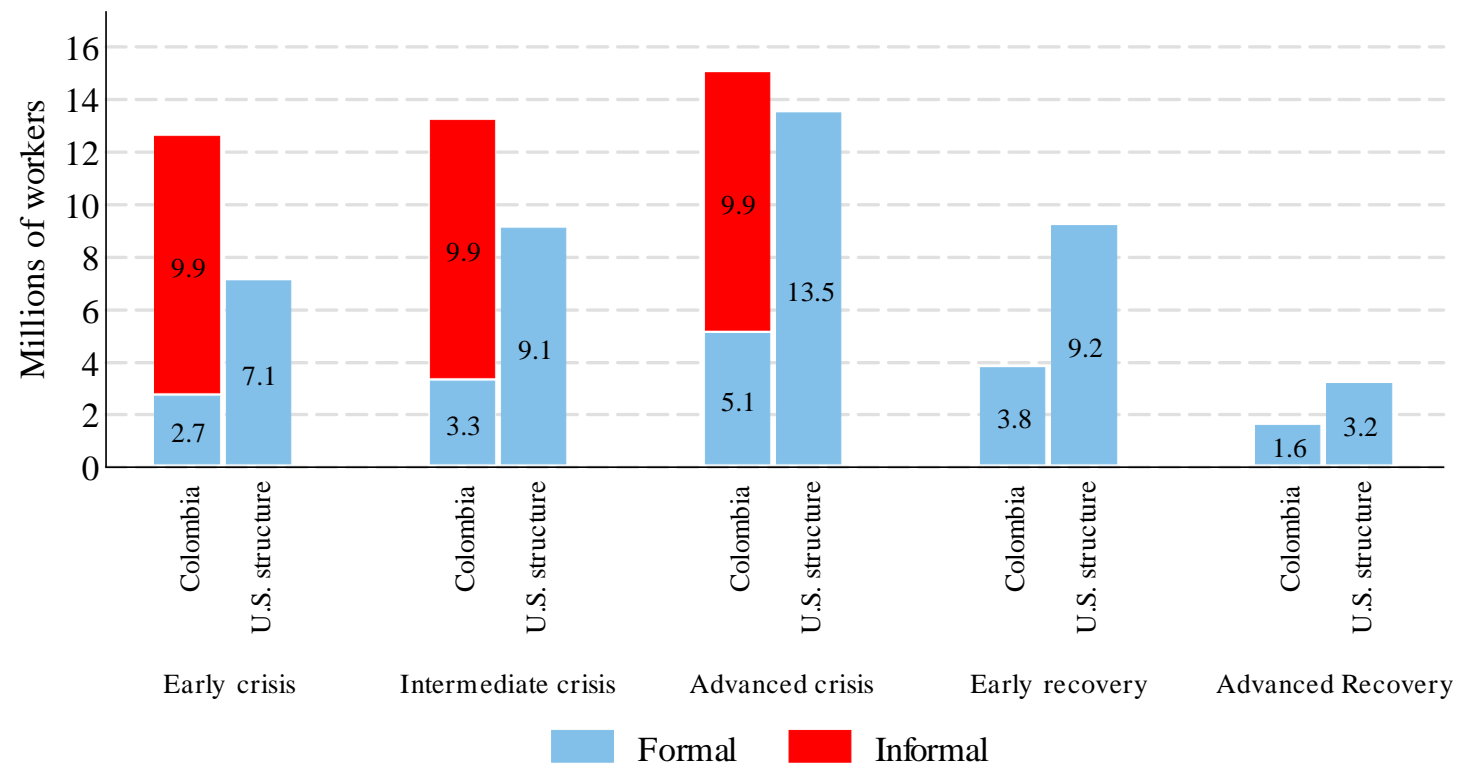

Notes: Early crisis: informal workers and workers in firms of up to 10 em ploy ees at risk.Intermediate crisis: workers in firms of up to 50 employ ees also at risk. Initial recovery: informal and self-employed re-enter. Advanced crisis: workers in firms of all sizes at risk. Advanced recovery: workers in large firms re-enter. The bars labeled "U.S. structure" recalculate Value Added at risk under the assumption that the distribution of workers is as in the U.S. between formal/informal status, in terms of firm size, and in terms of occupations.

To assess the importance of these dimensions of the economic structure in determining the magnitude of our Table 4 results, we run an alternative simulation where we change the economic structure of employment in Colombia to emulate the distribution of the U.S. economy. To do this, we alter the sample weights for observations in the GEIH to match the distribution of U.S. employment by industry, firm size, and economic sector based on the distribution of workers across occupations in the 2017 American Economic Survey (ACS), and their across sectors and firm sizes in the 2014 Business Dynamic Statistics (BDS). We assume that all employment reported in the US is formal.

Figure 4 presents the simulation results for employment. The less-developed economy structure implies much higher effects on employment in the short run yet a faster recovery. Moving the economic structure to that of the US yields an immediate employment exposure of 7.1 millions, which is much smaller than the exposure of 12.6 million under the Colombian employment distribution (33\% rather than $56 \%$ of baseline employment). The gaps between the effects under the two economic structures shorten as the crisis advances and employment in larger firms becomes affected, but jobs at risk still remain lower under the U.S. economic structure due to lower reliance on high 
contact in the US, thanks to the greater prevalence of occupations fit for telework. In the initial recovery period, the return of self-employed and informal sector workers generates a rapid rebound of employment under the Colombian economic structure, a gain relative to the U.S. structure that erodes as the economy moves to the advanced recovery period and medium-large firms, more prevalent in the US, go back to work. In both the crisis and the recovery horizons the differences with a more developed economy-like structure are mostly driven by the incidence of informality and self-employment, as shown by the formal/informal breakdown in the bar that corresponds to the Colombian economic structure.

The equivalent value-added results are presented in Figure 5. The differences in economic structure between Colombia and the US have a more modest effect on value added at risk than on jobs at risk. This is due to the low contribution of value added at risk from informal sector activities, the ones that explain the largest potential job losses in the crisis periods and the fast initial recovery under the Colombian economic structure. In the early crisis phase, the overall value added at risk in the baseline scenario is 33 trillion using the actual Colombian distribution of employment and 27 trillion using the counterfactual distribution. This is, respectively, $43 \%$ and $30 \%$ of the baseline 77 trillion of monthly value added captured by the household survey. In the advanced crisis phase, value-added at risk is, respectively, 47 trillion and 60 trillion under the Colombian and U.S. employment distributions.

Taken together, our simulation results in employment and value added suggest that the sheer size of the informal sector in developing economies exposes more people, precisely people who are not covered by automatic social security stabilizers, to immediate losses of their income. At the same time it should allow for faster recovery, compared to developed economies. To an extent, this faster recovery of some people's income is already seen in many countries of the developing world, as informal workers fail to continue complying with stay at home orders to make a living. But to the extent that poor enforcement of lockdowns for informal workers is compensated by stricter lockdown rules and stricter enforcement for the formal sector, the most highly productive segment of the economy, the recovery of aggregate output caused by the return to work of the informal is very limited.

\section{Discussion and Conclusions}

High informality and prevalence of microenterprises render emerging market economies more vulnerable to the COVID-19 crisis, which involves supply and demand shocks and propagation though the linkages network. Firms face financial contractions and potential reallocation effects. The perfect storm implied by this combination generates huge uncertainty about the duration of the crisis, which has proven not to be over or close to it. The extent of the economic devastation, however, is not independent of the policy options used to deal with the epidemic. 
Figure 5: Total Value Added At Risk Under Strict Lockdown Measure: All Shocks

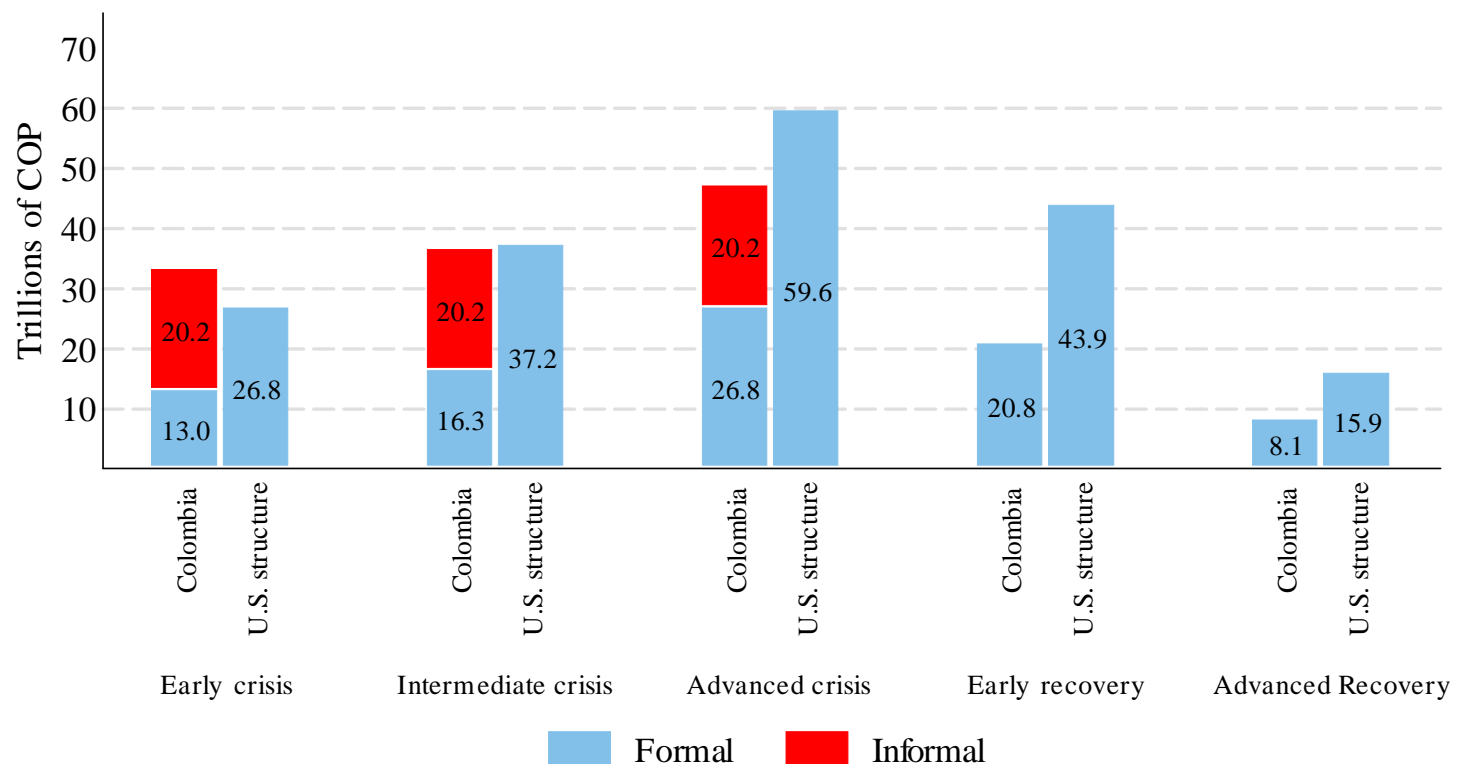

Notes: Early crisis: informal workers and workers in firms of up to 10 em ployees at risk.Intermediate crisis: workers in firms of up to 50 employ ees also at risk Initial recovery: informal and self-employed re-enter. Advanced crisis: workers in firm sof all sizes at risk. Advanced recovery: workers in large firms re-enter. The bars labeled "U.S. structure" recalculate Value Added at risk under the assumption that the distribution of workers is as in the U.S. between formal/informal status, in terms of firm size, and in terms of occupations. 
The pandemic has opened an important debate regarding how to isolate the economy through the crisis, and in particular, how best to support workers and firms. There has been a push to increase access to unemployment insurance to laid-off workers, support to sick workers and cash transfers to vulnerable populations. In addition, there has been widespread call, and use, of policies aiming to preserve formal employer-employee relationships by subsidizing some of the payroll costs to firms (OECD, 2020). Most of these programs are inspired by existing practices in developed countries, such as Germany's Kurzarbeitin, which allow for the flexibility to reduce the number of hours worked instead of terminating the employer relation, thus permitting companies to hold on to workers' know-how and experience.

The objective of such programs is to maintain jobs in firms that experience temporary closures or drops in demand, while providing income support to workers. The argument is that given fixed costs, and facing liquidity constraints, firms may inefficiently separate a higher number of workers. Based on organizational capital and skills externalities imbedded in the employer-employee match, maintaining these relations will accelerate the recovery in relation to other worker protection programs such unemployment insurance. Positive evidence of the effect of this type of practices is drawn from experience during the Global Financial Crisis and particular schemes and economic structures such as Germany's Kurzarbeitin (Boeri and Bruekcer, 2011). While related programs are currently being implemented in Germany, Denmark, France, and the UK, the current shock is different.

We argue that the benefits from subsidizing formal jobs, rather than just providing ex-post support via unemployment insurance, are exacerbated in Emerging Markets, where they constitute a small, laboriously built fraction of economic activity, and concentrate the bulk of society's organizational capital. In the face of widespread labor market rigidities, coupled with barriers to formal firm entry, these jobs will take long, potentially very long, to recover. Of course, policies should also aim to reduce the barriers to formality as a way to speed up a recovery that promises to be costly and lengthy. While informal workers are a very substantial fraction in these countries, the relative ease of restarting these jobs implies that the loss of income among the informal population is better addressed via income transfers than job protection schemes.

In addition, our results point to the extremely high costs of insisting on a strategy based solely on continued lockdowns to deal with the pandemia. The magnitude of potential employment and income effects is such that strategies to appropriately mitigate these effects, if their full potential is realized, will simply not be feasible. Effects must therefore be minimized, which requires limiting lockdowns as much as possible. Selective lockdowns based on age or economic activities have been proposed, but they are also highly problematic. First, households in EMEs are larger than in the developed world and varied in size composition, implying a larger contagion risk at home and rendering selective lockdowns less effective. The average household in middle income countries in Latin America, for instance, has close to 3.5 members, compared to close to 2.5 in the US, Italy and 
Spain, and just 2.1 in Germany. Meanwhile, over $70 \%$ of people above 65 live with younger people in Colombia. Age-based lockdowns are also subject to heated debate given the discriminatory treatment of people's liberties that they imply. Activity-based lockdowns, meanwhile, sever IO linkages making recovery more difficult.

It is therefore crucial that governments in EMEs decidedly adopt strategies that allow them to deal with the epidemia with minimum resort to lockdowns. These include well designed and scaled testing, tracing and isolation, as well as increases in the capacity of ICUs to receive COVID patients and of mass transport systems to move passengers minimizing crowds. Though increasing these capabilities is hard for the relatively weak states of emerging and developing economies, these difficulties are dwarfed by the sheer costs of lockdowns. Since their economic exposure is greater, the ammunition available to mitigate economic impacts more limited, and the capacity to enforce lockdowns weaker, governments in the developing world bear a particularly large responsibility to carefully assess the costs and benefits of these different options.

\section{References}

Acemoglu, D., Chernozhukov, V., Werning, I., and Whinston, D. (2020). A Multi-Risk SIR Model with Optimally Targeted Lockdown.

Alfaro, Laura and Marcela Eslava (2020) "Development and the Comparative Advantage of Services". Mimeo.

Alfaro, Laura, Andrew Charlton, and Fabio Kanczuk. (2009) "Plant-Size Distribution and Cross-Country Income Differences." In NBER International Seminar on Macroeconomics 2008, edited by Jeffrey A. Frankel and Christopher Pissarides. Cambridge, MA: National Bureau of Economic Research

Alfaro, Laura, Ester Faia, Nora Lamersdorf, Farzad Saidi Social Interactions in Pandemics: Fear, Altruism, and Reciprocity, NBER Working Paper No. 27134

Alfaro, Laura, Anusha Chari, Andrew N. Greenland, Peter K. Schott (2020) "Aggregate and Firm-Level Stock Returns During Pandemics, in Real Time," NBER Working Paper 26950

Alvarez, F., Argente, D., and Lippi, F. (2020). A Simple Planning Problem for COVID-19 Lockdown. CEPR W.P., 14658.

Atkeson, A. (2020, March). What will be the economic impact of covid-19 in the US? rough estimates of disease scenarios. Working Paper 26867, National Bureau of Economic Research.

Baqaee, David, and Emmanuel Farhi. 2020. "Supply and Demand in Disaggregated Keynesian Economies with an Application to the COVID-19 crisis". Working Paper,

Baqaee, David, and Emmanuel Farhi. 2020. "Nonlinear Production Networks with an Application to the COVID-19 crisis". Working paper. 
Barrero, Jose Maria and Bloom, Nicholas and Davis, Steven J. (2010) "COVID-19 Is Also a Reallocation Shock", NBER Working Paper No 27167.

Bartik, A. W., M. Bertrand, Z. Cullen, E. L. Glaeser, M. Luca, and C. T. Stanton (2020). How are small businesses adjusting to covid-19? early evidence from a survey. NBER w26989.

Barrot, Jean-Noel and Grassi, Basile and Sauvagnat, Julien, Sectoral Effects of Social Distancing (April 2, 2020).

Bento, Pedro. and Restuccia, Diego (2020) "On Average Establishment Size across Sectors and Countries." Journal of Monetary Economics.

Bernal, R. "The Informal Labor Market in Colombia: identification and characterization". Revista Desarrollo y Sociedad, no. 63 (2009): 145-208.

Boeri, T. and HJ. Bruecker (2011) "Short-time work benefits revisited: Some lessons from the Great Recession," Economy Policy 26 (68): 697-765

Cajner, T., L. D. Crane, R. A. Decker, A. Hamins-Puertolas, and C. Kurz (2020). Tracking labor market developments during thecovid-19 pandemic: A preliminary assessment. Finance and Economics Discussion Series 2020-030 .

Coibion, O., Y. Gorodnichenko, and M. Weber (2020). Labor markets during the covid-19 crisis: A preliminary view. NBER w27017

Davis, S. J. and T. von Wachter (2011) "Recessions and the cost of job loss," Brookings Papers in Economic Activity 43(2): 1-72.

Dingel, J. I., \& Neiman, B. (2020). How many jobs can be done at home? NBER Working paper No. 26948.

Eslava, M, J. Haltiwanger and A. Pinzón (2019) “Job Creation in Colombia vs the U.S.: 'Up or out Dynamics' Meets 'The Life Cycle of Plants." NBER WP 25550.

Eslava, M, and J. Haltiwanger (2019) "The Life-cycle Growth of Plants: The Role of Productivity, Demand and Wedges." SSRN Working Paper.

Haltiwanger, John, Ron Jarmin, and Javier Miranda (2013) "Who Creates Jobs? Small vs. Large vs. Young." Review of Economics and Statistics, 95(2), 347-361.

Haltiwanger, John, Ron Jarmin, and Javier Miranda (2013) "Who Creates Jobs? Small vs. Large vs. Young." Review of Economics and Statistics, 95(2), 347-361.

Eslava, M. John Haltiwanger and Alvaro-Jose Pinzon (2019) Job Creation in Colombia vs the U.S.: 'Up or out Dynamics' Meets 'The Life Cycle of Plants'. NBER Working Paper 25550.

Hsieh, Chang-Tai. and Olken, Benjamin A. (2014) "The Missing "Missing Middle."” Journal of Economic Perspectives, vol. 28 (3), pp. 89-108.

Hsieh, Chang-tai and Peter Klenow (2014) "The Life Cycle of Plants in India and Mexico, "Quarterly Journal of Economics 129, 035-1084.

Hsieh, Chang-tai and Peter Klenow (2009) "Misallocation and Manufacturing TFP in China and India, "Quarterly Journal of Economics 124, 1403-1448. 
Humphries, J. E., C. Neilson, and G. Ulyssea (2020). The evolving impacts of covid-19 on small businesses since the cares act. working paper.

La Porta, R., and A. Shleifer. (2014). Informality and development. Journal of Economic Perspectives, 28(3), 109-26.

Leibovici, F., Santacreu, A. M., \& Famiglietti, M. (2020). Social distancing and contact-intensive occupations. On the Economy, St. Louis FED.

Magnac, T. (1991). Segmented or Competitive Labor Markets. Econometrica, 59(1), 165-187.

Maloney, W. F. (1999). Does informality imply segmentation in urban labor markets? Evidence from sectoral transitions in Mexico. The World Bank Economic Review, 13(2), 275-302.

Meghir, C., Narita, R., and Robin, J. M. (2015). Wages and informality in developing countries. American Economic Review, 105(4), 1509-46.

OECD (2020) Policy Responses to Coronavirus (COVID-19), "Supporting people and companies to deal with the COVID-19 virus: Options for an immediate employment and social-policy response." March.

http://www.oecd.org/coronavirus/policy-responses/supporting-people-and-companies-to-deal-withthe-covid-19-virus-options-for-an-immediate-employment-and-social-policy-response-d33dffe6 /

Perry, G., O. Arias, P. Fajnzylber, W. Maloney, A. Mason, and J. Saavedra-Chanduvi. Informality: Exit and exclusion. The World Bank, 2007.

Poschke, Markus (2018) "The Firm Size Distribution across Countries and Skill-Biased Change in Entrepreneurial Technology." American Economic Journal: Macroeconomics, vol. 10 (3), pp. $1-41$.

Tybout, James R. 2000. "Manufacturing Firms in Developing Countries: How Well Do They Do, And Why?" Journal of Economic Literature 38(1): 11-44. 
Table A1: Sweden: Fraction of consumers reporting increases vs. spending decreases

\begin{tabular}{|c|c|c|}
\hline McKinsey spending category & Sector & $\begin{array}{c}\text { Change } \\
\text { Fraction } \\
\text { Spending }^{1}\end{array}$ \\
\hline Groceries & Agriculture, forestry and fishing & 3 \\
\hline Snacks & Agriculture, forestry and fishing & -14 \\
\hline Tobacco & Tobacco products & -14 \\
\hline Food Takeout \& delivery & Accommodation and food service & -12 \\
\hline Alcohol & Beverages & -22 \\
\hline Quick-service restaurant & Accommodation and food service & -46 \\
\hline Restaurant & Accommodation and food service & -63 \\
\hline Footwear & Leather and related products & -42 \\
\hline Apparel & Wearing apparel & -39 \\
\hline Jewelry & Wearing apparel & -42 \\
\hline Accesories & Wearing apparel & -46 \\
\hline Non-food child products & Wholesale, basic goods & -7 \\
\hline Household supplies & Wholesale, basic goods & -9 \\
\hline Personal-care products & Wholesale, basic goods & -6 \\
\hline Skin care \& makeup & Wholesale, basic goods & -26 \\
\hline Furnishing \& appliances & Wood and products of wood & -46 \\
\hline Entertainment at home & Arts, entertainment and recreation & 6 \\
\hline Books/magazines/newspapers & Paper and paper products & -18 \\
\hline Consumer electronics & Computer and electronic products & -32 \\
\hline out-of-home entertainment & Arts, entertainment and recreation & -75 \\
\hline Pet-care services & Arts, entertainment and recreation & -35 \\
\hline Fitness \& wellness & Arts, entertainment and recreation & -43 \\
\hline Personal-care services & Arts, entertainment and recreation & -45 \\
\hline Gasoline & Coke, refined petrol, and chemicals & -24 \\
\hline Vehicle purchases & Wholesale, retail, repair of vehicles & -46 \\
\hline Short-term home rentals & Accommodation and food service & -69 \\
\hline Travel by car & Passenger transport & -31 \\
\hline Cruises & Passenger transport & -67 \\
\hline Adventures \& tours & Passenger transport & -66 \\
\hline International flights & Passenger transport & -80 \\
\hline Hotel/restor stays & Accommodation and food service & -80 \\
\hline Domestic flights & Passenger transport & -76 \\
\hline
\end{tabular}

${ }^{1}$ Fraction reporting more spending minus fraction reporting less spending. Source: Own calculations based on McKenzie's (2020) Consumer Survey. 


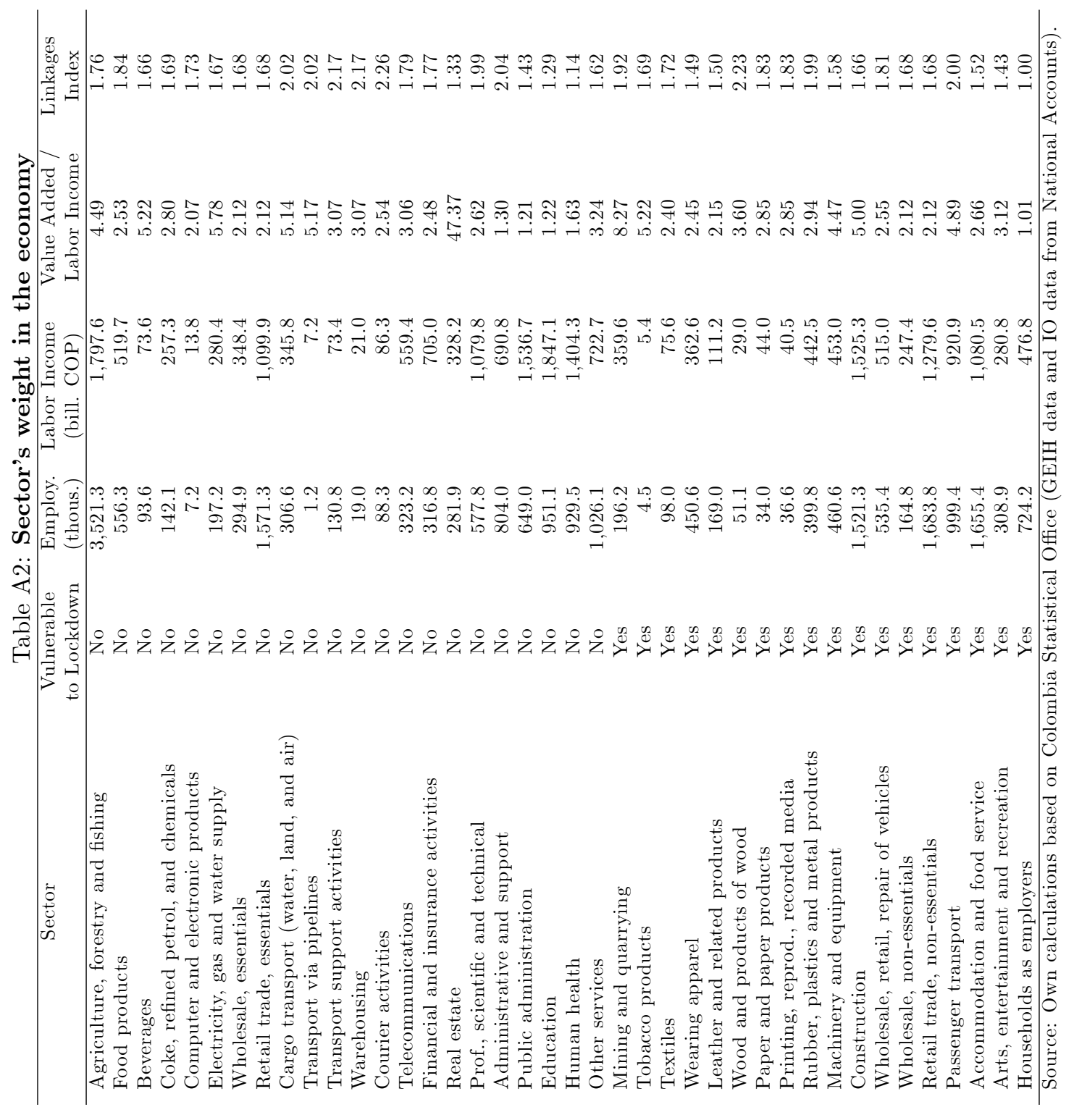




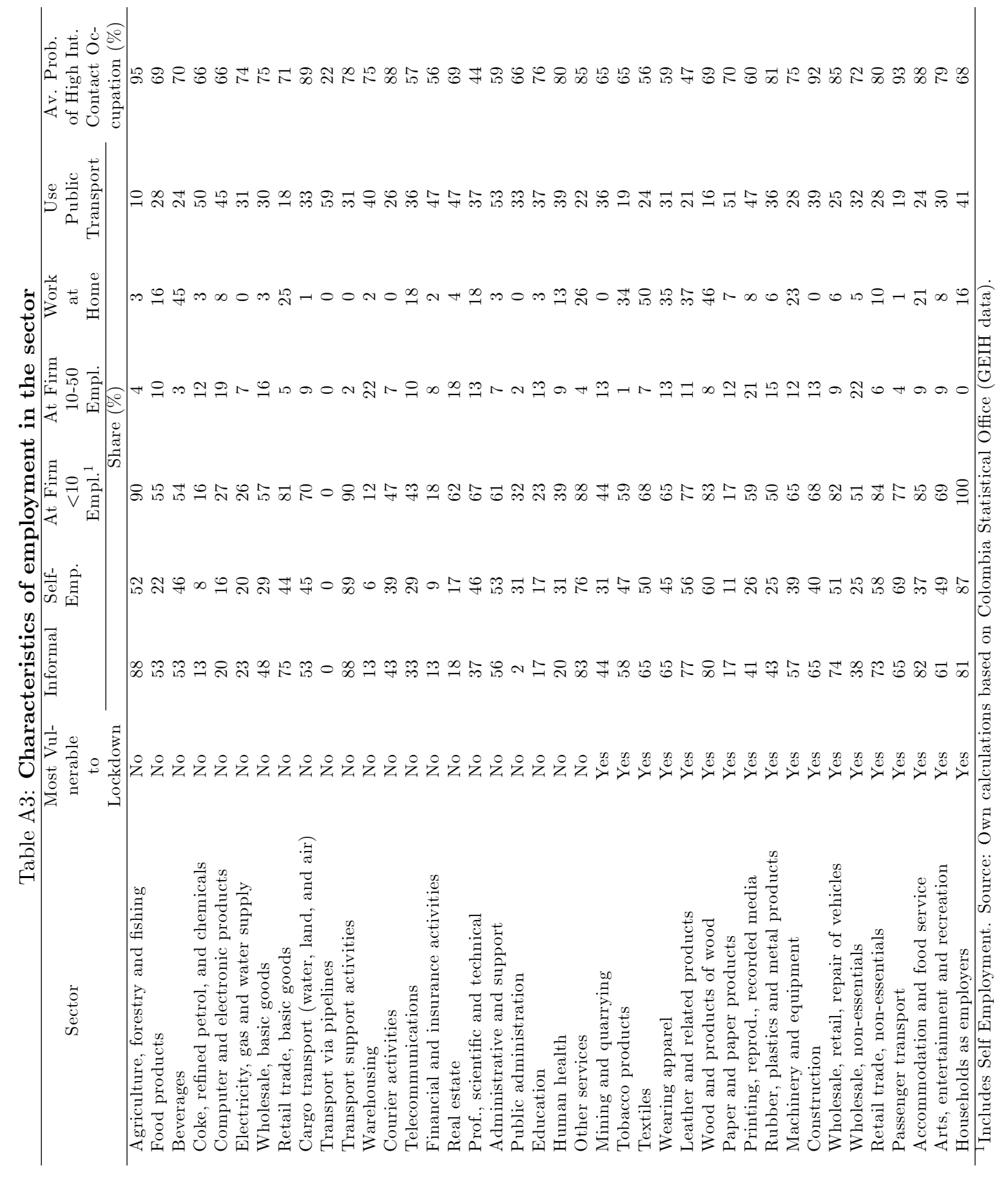




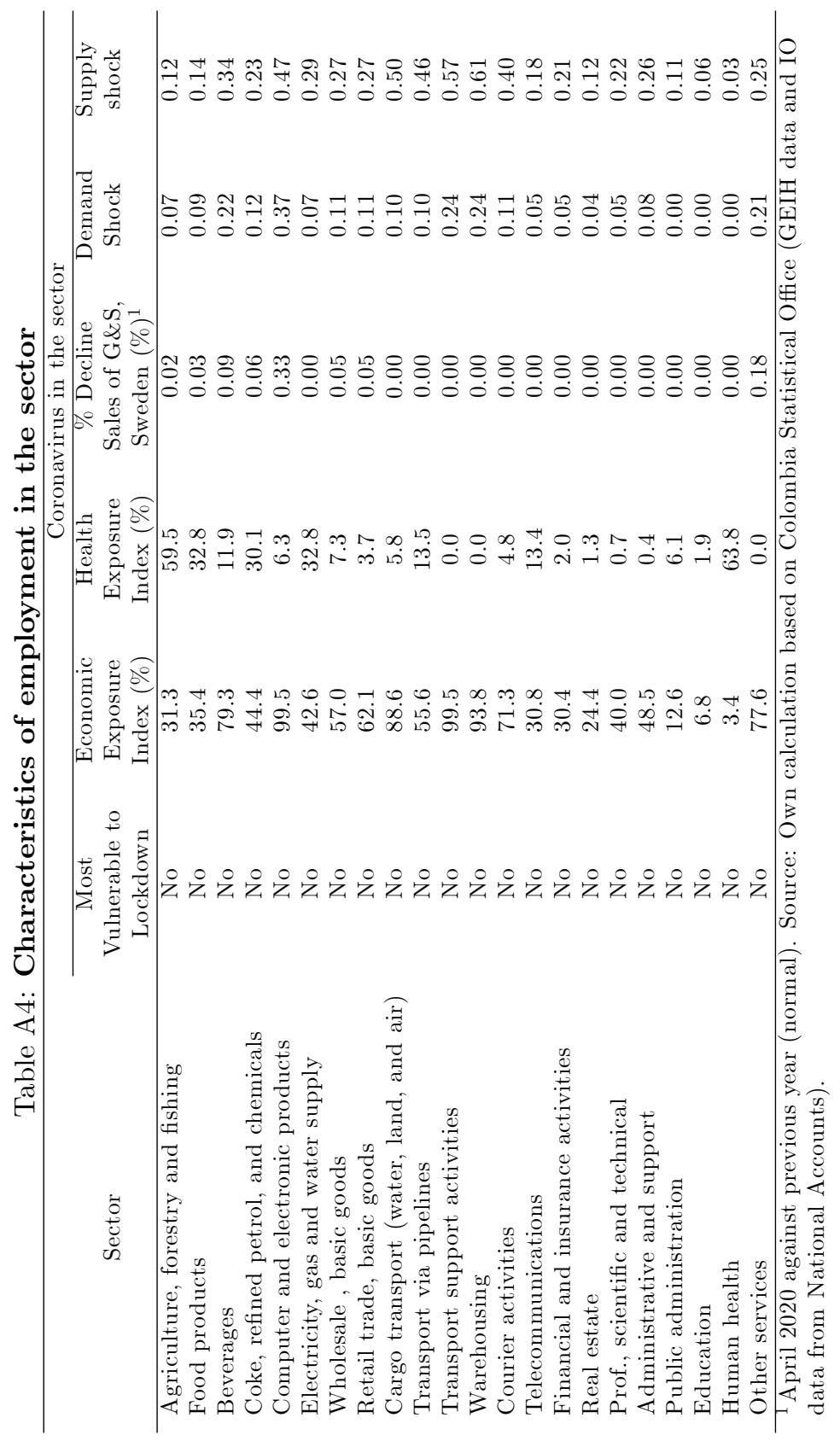




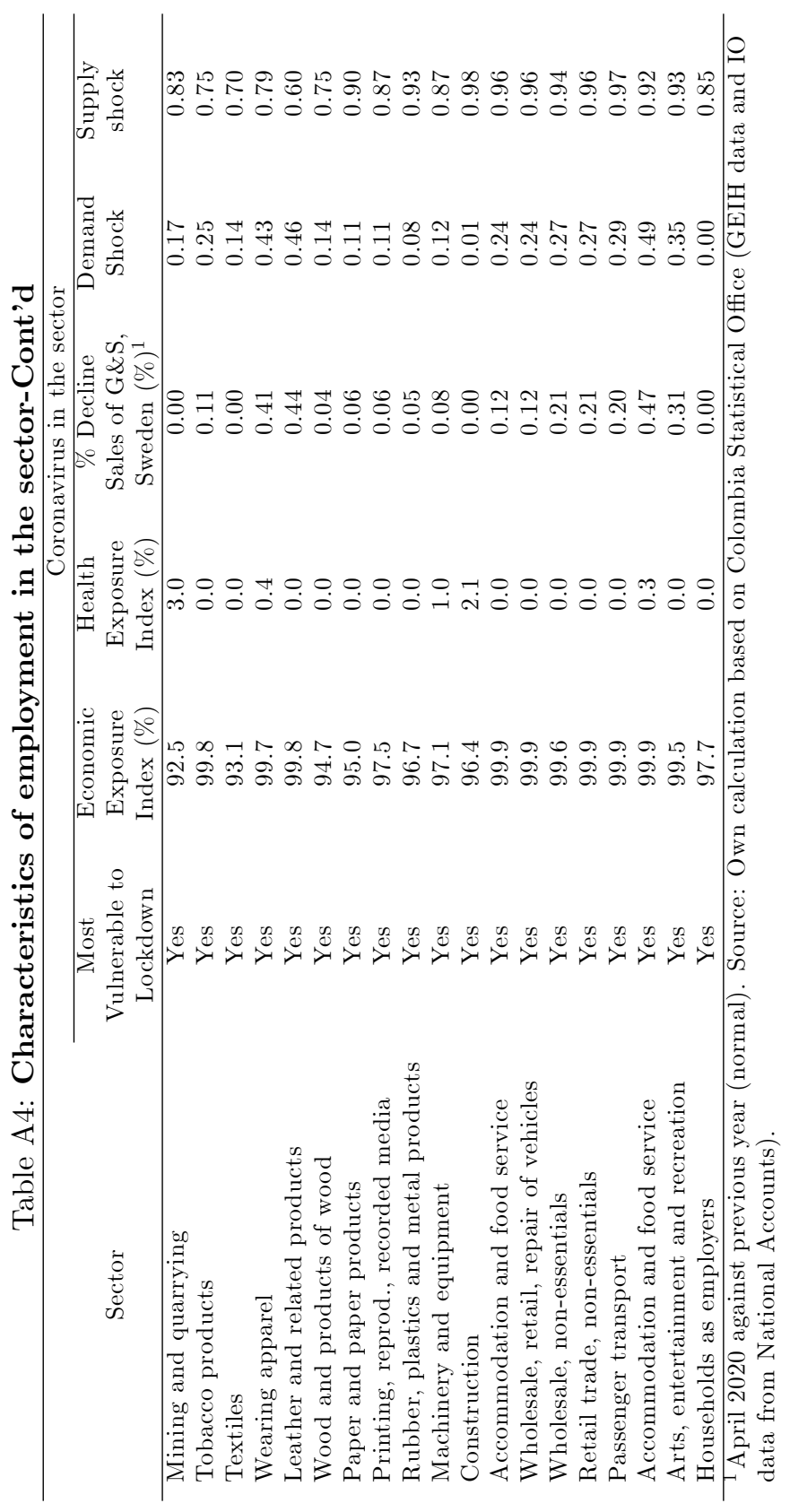

